\title{
Just the once will not hurt: DNA suggests species lumping over two oceans in deep-sea snails (Cryptogemma)
}

\author{
Zaharias Paul ${ }^{1,}{ }^{*}$, Kantor Yuri, I ${ }^{2}$, Fedosov Alexander E. ${ }^{2}$, Criscione Francesco ${ }^{3}$, Hallan Anders ${ }^{3}$, \\ Kano Yasunori ${ }^{4}$, Bardin Jeremie ${ }^{5}$, Puillandre Nicolas ${ }^{1}$
}

${ }^{1}$ Sorbonne Univ, Inst Systemat Evolut Biodiversite ISYEB, Museum Natl Hist Nat, CIVRS,EPHE,Univ Antilles, 43 Rue Cuvier,CP 26, F-75005 Paris, France.

${ }^{2}$ Russian Acad Sci, AN Severtsov Inst Ecol \& Evolut, Leninski Prospect 33, Moscow 119071, Russia.

${ }^{3}$ Australian Museum Sydney, Australian Museum Res Inst, Sydney, NSW 2010, Australia.

4 Univ Tokyo, Atmosphere \& Ocean Res Inst, 5-1-5 Kashiwanoha, Kashiwa, Chiba 2778564, Japan.

${ }^{5}$ Sorbonne Univ, Ctr Rech Paleontol Paris CR2P, UMR 7207, CNRS,MNHN, Site Pierre \& Marie Curie, 4 PI Jussieu, Paris 05, France.

* Corresponding author : Paul Zaharias, email address : paul.zaharias@edu.mnhn.fr

\begin{abstract}
:
The practice of species delimitation using molecular data commonly leads to the revealing of species complexes and an increase in the number of delimited species. In a few instances, however, DNA-based taxonomy has led to lumping together of previously described species. Here, we delimit species in the genus Cryptogemma (Gastropoda: Conoidea: Turridae), a group of deep-sea snails with a wide geographical distribution, primarily by using the mitochondrial $\mathrm{COI}$ gene. Three approaches of species delimitation (ABGD, mPTP and GMYC) were applied to define species partitions. All approaches resulted in eight species. According to previous taxonomic studies and shell morphology, 23 available names potentially apply to the eight Cryptogemma species that were recognized herein. Shell morphometrics, radular characters and geographical and bathymetric distributions were used to link type specimens to these delimited species. In all, 23 of these available names are here attributed to seven species, resulting in 16 synonymizations, and one species is described as new: Cryptogemma powelli sp. nov. We discuss the possible reasons underlying the apparent overdescription of species within Cryptogemma, which is shown here to constitute a rare case of DNA-based species lumping in the hyper-diversified superfamily Conoidea.
\end{abstract}

Keywords : species delimitation, species description, ABGD, GMYC, PTP, deep-sea species, larval dispersal, cosmopolitan species 


\section{Introduction}

2 The advent of integrative taxonomy (Dayrat, 2005; Will et al., 2005), mainly driven by

3 the molecular revolution, has led to a great remodeling of the practice of species

4 delimitation, extending the use of standardized approaches in the field of taxonomy (e.g.

5 Lefébure et al., 2006). Several resulting studies, often primarily based on molecular

6 data, have revealed numerous species complexes, thus increasing the number of

7 delimited species within such groups, commonly referred to as "cryptic species"

8 (Bickford et al., 2007; Fišer et al, 2017). The difficulty in assigning names and/or

9 describe these newly delimited species can constitute an impediment, especially for

10 non-taxonomists. Indeed, when new species are discovered, nearly half of them remain

11 undescribed, at least not described in the publication where they are revealed (Pante et

12 al., 2014). Thus, the splitting effect of integrative taxonomy is not accompanied by

13 adequate taxonomic effort, resulting in a plethora of undescribed species. It has been

14 suggested that such lack of appropriate taxonomic procedure can have consequences in

15 various fields, such as ecology and conservation (e.g. Iglésias et al., 2010).

16 Conversely, there have been cases where integrative taxonomy, by incorporating

17 molecular data, has led to the lumping of species that have been originally described

18 using morphological and anatomical characters only (e. g. Chan et al., 2018; Dejaco et

$19 a l ., 2016)$. Such instances may occur when, contrary to the occurrence of "cryptic

20 species", intra-specific morphological variability is equal to or greater than inter-

21 specific variability (e.g. Puillandre et al., 2010). These phenomena may have biological

22 causes (e.g. sexual dimorphism, allometry during ontogeny, phenotypic plasticity), or in

23 other cases simply be artefacts of a particular taxonomic practice (some taxonomists

24 tend to split more than others). Unfortunately, these cases are difficult to investigate for 
taxa where morphological characterization is not formalized, genomic resources are poor, and/or known specimens are rare and deposited in different institutions.

Nevertheless, investigating whether or not different forms correspond to different species should rely on a combination of modern species delimitation approaches and solid taxonomic expertise in order to clarify both boundaries and taxonomic status of a given taxon.

The Conoidea (Neogastropoda) is an extremely diversified lineage of marine gastropods, traditionally divided into Terebridae, Conidae and Turridae (Bouchet et al., 2011). Recent molecular phylogenies have significantly redefined boundaries within the superfamily (Puillandre et al., 2011; Abdelkrim et al., 2018a), leading to a redefinition of the turrids. The family Turridae H. Adams \& A. Adams, 1853 (1838) is now a monophyletic group that encompasses a few morphologically well-defined monophyletic genera, such as Gemmuloborsonia, Polystira, Lophiotoma or the "Xenuroturris/Iotyrris complex", that have been revised in recent years (Puillandre et al, 2010; Todd \& Rawlings, 2014; Puillandre et al., 2017; Abdelkrim et al., 2018b). In some cases, the integrative taxonomy approach has uncovered "cryptic species" that were described in the same studies in which they were revealed. However, a considerable proportion of turrid species are still left in the paraphyletic genus Gemmula, for which it was estimated that less than half the number of species has been described so far (Puillandre et al., 2012). Puillandre et al. (2012) also called for the complete revision of Gemmula, and suggested that the high number of species and the suspected global morphological stasis of the group are likely explanations as to why this group remains unrevised until now. Moreover, revising the Gemmula group would be tantamount to revising the entire Turridae, given that independent "Gemmula-like" 
49 lineages are distributed all over the turrid tree (Puillandre et al. 2012). Finally, while a

50

51

52 high number of undescribed species was estimated in Gemmula, it is not clear whether all the independent "Gemmula-like" lineages equally include undescribed species, or if some lineages will require splitting of previously described species, while others will imply lumping of previously described species, or a combination of both splitting and lumping. Hence, we propose to partition the taxonomic revision by focusing on smaller monophyletic groups that would be revised one by one, in order to progressively resolve the taxonomic predicament of Gemmula as it presently stands. The first group we identified is a clade of deep-water species, hereafter named "Cryptogemma", that has already been used as a case-study to illustrate congruent species hypotheses in the integrative taxonomy framework designed in Puillandre et al. (2012, Figure 5), comprising five species of Turridae attributed to three genera. We completed the dataset from Puillandre et al. (2012) with recent field sampling and material from museums, and applied an integrative taxonomy approach primarily based on the analysis of barcode fragment of $C O I$ with additional data on the geography and bathymetry included a posteriori to help attributing existing names to the molecular species hypotheses. Furthermore, we significantly improved resolution of morphological studies by carrying out a formalized analysis of the morphology of teleoconch and protoconch, and by examining radulae in all sequenced species. The sequencing of a few type specimens and the formalized morphological analysis allowed us to attribute confidently type specimens to molecular species. Our results enabled a comprehensive revision of Cryptogemma: rather than finding the usual splitting effect of molecularbased integrative taxonomy, our study led to an unexpected number of new synonymies and only one new species description. 


\section{Material and Methods}

75

76

77

78

79

80

81

82

83

84

85

86

87

88

89

90

91

92

93

94

95

96

The integrative taxonomy pipeline followed in this study comprises three main steps.

First, most samples were sequenced at least for the $\mathrm{CO} 1$ gene fragment, without

necessary being preliminarily identified morphologically to the species level. Second, automated species delimitation methods were used to delimit molecular operational taxonomic units (MOTUs), resulting in primary species hypotheses. Finally, MOTUs were assessed using alternative gene fragments, morphology, geography and bathymetry, resulting in final species hypotheses.

\section{Sampling}

As a part of our background activity, most neogastropods collected during field expeditions organized by the Muséum national d'Histoire naturelle (MNHN) are processed for DNA extraction and sequencing of the Barcode fragment of the COI gene. Among the processed material, all specimens for whom the barcode sequences clustered into the Cryptogemma clade were included in this study. These samples were collected during field expeditions in the Indo-Pacific and West Atlantic: EBISCO and KANADEEP in the Chesterfield Islands, CONCALIS, EXBODI, KANACONO, TERRASSES and NORFOLK 2 in New-Caledonia, MIRIKY and ATIMO VATAE in Madagascar, MAINBAZA in Mozambique, BIOMAGLO in Mayotte, BIOPAPUA, KAVIENG, MADEEP and PAPUA NIUGINI in Papua New Guinea, AURORA 2007 and PANGLAO 2004 in the Philippines, SALOMON 2 and SALOMONBOA 3 in the Salomon Islands, TARASOC in the Société-Tuamotu islands, TAIWAN 2013, NANHAI 2014, DONGHA 2014 and ZHONGSHA 2015 in Taiwan, GUYANE 2014 in French Guyana. Additional samples were collected during Japanese expeditions: T/V 
97 “Nagasaki-maru” cruise N275 and R/V "Tansei-maru” cruise KT-12-32 in Japan. We

98

99

completed this sampling with specimens from the Australian museum (AMS),

Zoological Museum of Moscow State University (ZMMU) and the National Museum of Natural History (USNM) that could potentially belong to this clade, based on their morphology and the available corresponding sequence in GenBank. Twelve specimens from the AMS were collected during the IN2017_V03 - Sampling the Abyss cruse (2017). A paratype of Ptychosyrinx lordhoweensis Kantor \& Sysoev, 1991 (R/V “Dmitry Mendeleev", 16th cruise, st. 1245, º Lc14353; Kantor \& Sysoev, 1991) from the ZMMU was used for DNA extraction. Samples from USNM were also selected for molecular analyses: three paralectotypes of Gemmula benthima Dall, 1908 (USS Albatross; Stations 2807, 3360, 3365, USNM N 96485, 123087, 123092; Kabat, 1996) and one specimen of Ptychosyrinx carynae (Haas, 1949), USNM 832922. For USNM samples, G. benthima specimens were preserved dry, while the P. carynae specimen was probably fixed in formalin before conservation in ethanol.

MNHN specimens processed before 2012 as well as all AMS specimens chosen for molecular analysis were anaesthetized using the isotonic solution of $\mathrm{MgCl}_{2}$ prior to fixation in $96 \%$ ethanol. MNHN specimens processed after 2012 were microwaved and fixed in 96\% ethanol (Galindo et al., 2014). In some cases, shells were subsequently drilled to extract the retracted animals. Japanese specimens were boiled in $70-90^{\circ} \mathrm{C}$ water for $0.1-0.5 \mathrm{~min}$ before preservation in 99\% ethanol. ZMMU specimens were probably fixed and preserved in $75-80 \%$ ethanol.

\section{DNA sequencing}


DNA from MNHN samples was extracted using the Epmotion 5075 robot (Eppendorf), following the manufacturers' recommendations. DNA from AMS samples was extracted from small pieces of foot muscle by use of a Bioline Isolate II Genomic DNA extraction kit for animal tissue, following the standard procedure of the manual. DNA from ZMMU and USNM samples was extracted using the EZNA Mollusc DNA Kit (Omega Bio-Tek Inc.), following the manufacturers' recommendations. For most samples, the barcode fragment (658 bp) of the mitochondrial COI gene was amplified using the universal primers LCO1490/HCO2198 (Folmer et al., 1994). PCR reactions were performed using a previously well-established protocol (Puillandre et al., 2017). For the ZMMU and USNM samples, the barcode fragment was amplified in two fragments, one with the LCO1490 and a newly designed primer (conoCOIintR: GCNCATGCHGGNGGNTCWGTW) and the other with another newly designed primer (conoCOIintF: TCWTCAGCTGCNGTWGAAAGNGG) and the HCO2198 primer. Both fragments are overlapping over $\sim 50$ nucleotides. The PCR mix was the same as for the LCO1490/HCO2198, except that BSA $(10 \mathrm{mg} / \mathrm{mL})$ was used instead of DMSO. The amplification procedure was also similar, except that the annealing temperature was $47^{\circ} \mathrm{C}$, with 40 cycles instead of 35 . A fragment of the mitochondrial $12 S$ rRNA gene was amplified using the universal primers $12 S 1 / 12 S 3$ (Simon, Franke \& Martin, 1991) and PCR reactions performed using a previously established protocol (Puillandre et al., 2011). PCR products were purified and sequenced by the Eurofins sequencing facility. $28 S$ primers used at AMS were C1'/D2 (Dayrat et al., 2001; Jovelin \& Justine, 2001). Amplification of $28 S$ consisted of an initial denaturation step at $94{ }^{\circ} \mathrm{C}$ for $4 \mathrm{~min}$, followed by 30 cycles of denaturation at $94{ }^{\circ} \mathrm{C}$ for $30 \mathrm{~s}$, with annealing set to 
$57^{\circ} \mathrm{C}$ for $45 \mathrm{~s}$, followed by extension at $72{ }^{\circ} \mathrm{C}$ for $1 \mathrm{~min}$. The final extension was at 72 ${ }^{\circ} \mathrm{C}$ for $5 \mathrm{~min}$.

\section{Species delimitation}

COI sequences were aligned manually using MEGA X (Kumar et al., 2018); $12 S$ and $28 S$ sequences were aligned using Muscle (Edgar, 2004) as implemented in MEGA X and then checked by eye. Phylogenetic reconstruction methods were applied to the $C O I$ alignment, plus a concatenation of the $C O I, 12 S$ and $28 S$ alignments with one specimen per species (see Results section).ABGD, GMYC and mPTP methods were applied to the $\mathrm{CO} 1$ dataset. All three methods are exploratory and aim at finding clusters of specimens corresponding to species but differ strongly in several aspects. ABGD is based on genetic distances only and automatically detects the gap (the so-called "barcode gap") between intra and interspecific distances, then used to delimit species hypotheses. On the contrary, GMYC and mPTP rely on phylogenetic trees. GMYC uses an ultrametric tree and looks for a transition between speciation and coalescent nodes. mPTP also delimit species by identifying the transition between the inter and intraspecific parts of the tree, but requires only a phylogeny with branch length being proportional to the number of substitutions, and relies on the mutation rate instead of the branching rate.

For ABGD, the web version (http://wwwabi.snv.jussieu.fr/public/abgd/) and the default parameters were used, with a Kimura (K80) TS/TV model implemented. Maximum likelihoods trees were constructed for $\mathrm{COI}$, and the concatenated $(\mathrm{COI}+12 \mathrm{~S}+28 \mathrm{~S})$ alignments using IQ-TREE v1.6.3 (Nguyen et al. 2014), with 100 bootstraps. For all alignments, $\mathrm{COI}$ was consistently divided into three partitions, corresponding to the 
three codon positions, and $12 S$ and $28 S$ considered each as a single partition. The best model for each partition was evaluated using ModelFinder as implemented in IQ-TREE (Kalyaanamoorthy et al., 2017). The mPTP approach of species delimitation (Kapli et $a l ., 2017)$ was performed on the COI maximum likelihood tree, using both ML delimitation with default parameters and MCMC method with a Markov chain of $200,000,000$ generations, a sampling frequency each 2,000 generations and a burnin set at 25\%. Bayesian trees were reconstructed using BEAST v2.5.0 (Bouckaert et al., 2019), running 200,000,000 generations on the COI dataset with a sampling frequency every 4,000 generations and a burnin set at $10 \%$. The COI dataset was partitioned by codon position for model evaluation, and prior values were set as in Puillandre et al. (2017). The resulting trees were combined using TreeAnnotator as implemented in BEAST2, with node heights corresponding to mean heights of all trees. The "single threshold" method of GMYC was applied using the resulting tree. Finally, a nonultrametric Bayesian tree was reconstructed for the $C O I$, and concatenated datasets using MrBayes v3.2.6 (Ronquist \& Huelsenbeck, 2003), each of the two runs consisting of 8 Markov chains and 20,000,000 generations and a sampling frequency each 2,000. The analysis was performed on the Cipres Science Gateway (http://www.phylo.org/portal2). The consensus tree was calculated with burnin set at $20 \%$.

Four species of Turridae were used as outgroups: Turris babylonia (Linnaeus, 1758), Gemmula kieneri (Doumet, 1840), Unedogemmula unedo (Kiener, 1839) and Turridrupa sp. The MolD program (Fedosov et al., 2019) was used to identify unique combinations of diagnostic sites for each delimited species. 
191

192

\section{Shell and radular morphology}

Radulae were prepared by standard methods (Kantor \& Puillandre, 2012) and examined by scanning electron microscopes JEOL JSM 840A and Tescan VEGA II LSU at the MNHN. Protoconchs and shells were measured in standard position and the number of protoconch whorls counted according to Bouchet \& Kantor (2004).

Variation of shell shapes was analyzed through their outlines. Initially, we made a selection of shells of sequenced specimens that were not broken, truncated or aberrant. To complete this dataset, we obtained photographs of 20 name-bearing types (corresponding to 21 species names) that were deemed high-quality, of which 18 were suitable for morphometric analysis (nearly complete shells). In total, shape acquisition was performed for 197 sequenced specimens, 18 types and 8 unsequenced specimens of C. periscelida.

Shell shape was acquired from photographs using a Photoshop CC 2019 script. Outlines were reconstructed with the package Momocs (Bonhomme et al. 2014) from the $\mathrm{R}$ software. We used Elliptical Fourier analysis (Giardina and Kuhl, 1977), which presents many advantages over alternative Fourier analyses (Bonhomme et al. 2014), to decompose the closed outlines of the shells into periodic functions. The number of harmonics necessary to describe the shape was selected to reach $99.9 \%$ of the cumulative harmonic power, ensuring that the majority of shell shape outlines were considered. Shapes were also checked by eye to ensure that enough complexity was captured. The obtained coefficients were normalized to allow the superposition of the first ellipse and make the shapes comparable. We checked that all the reconstructed outlines were appropriately aligned. A principal component analysis (PCA) was performed on the harmonics coefficients in order to capture an optimal shape variation 
with a minimal number of principal components. Finally, a linear discriminant analysis (LDA) was performed to find the linear combination of principal components that maximizes difference between specimens from species delimited with DNA. Fourier analysis does not take size into account; only shapes are compared. As the size of the shells may provide some discriminatory information, we added the length of each specimen as a variable for the LDA. The appropriate number of principal components to use in the LDA model was carefully chosen to find optimal equilibrium between maximizing the differences and overfitting. A leave-one-out cross-validation procedure was used to find the number of PC axes leading to the best percentage of species predictions (see Figure S1). In order to test if our species attribution to each molecular species partition was correct, type specimens were not included in the LDA training set but subsequently added in the LDA morphospace. Another reason not to include the types in the training set was to extract at best the morphological differences between molecular species without the influences of type specimens morphology. All the material examined for this study is summarized in Table S1.

\section{Results}

A total of $303 \mathrm{COI}, 3228 S$ and $1812 S$ sequences of Cryptogemma were used for this study, of which respectively 255,8 and 16 were newly obtained. The USNM and ZMMU samples yielded poor DNA quality, making them difficult to sequence with a classical Sanger sequencing approach. Nevertheless, the $12 S$ was obtained for the USNM96485 and USNM123087 paralectotypes of Gemmula benthima collected 128 years ago. For the ZMMU paratype, the USNM123092 paralectotype and the 
239 USNM83292 lot of Ptychosyrinx carynae, the COI was obtained using the

240 conoCOIintR and conoCOIintF newly designed primers. The USNM123092 lot had

241 previously been sequenced and published by Todd \& Rawlings (2014) for the COI and

$24212 S$ fragments (GenBank accession number KM218745, KM218648), despite the fact

243 that the samples were most probably formalin-fixed. Nevertheless, sequencing an

244 additional specimen from the same lot was necessary as the lot might include specimens

245 from different species.

246 All ABGD, mPTP and GMYC analysis (see Figure S2) on the COI dataset resulted in

247 the same partition with eight species hypotheses. Both COI and $28 S$ proved, in this

248 clade, to be appropriate markers for species delimitation, confirming the five COI-based

249 species hypothesis (C. praesignis, C. timorensis, C. tessellata, C. unilineata and C.

250 powelli sp. nov.) in Puillandre et al. (2012). However, new $28 S$ sequences were not

251 produced here. The $28 S$ sequencing of $C$. aethiopica and C. periscelida failed, but these

252 two species are well recognizable morphologically and are not genetically close to a

253 sister species, making it less probable that the COI-based species hypotheses are

254 incorrect. The case of $C$. praesignis and C. phymatias could be considered problematic

255 as they are found to be sister species and are separated bathymetrically. However, the

256 single sequence of $28 S$ recovered for C. phymatias (C571715) showed a divergence

257 with the available $28 S$ sequences of $C$. praesignis comparable to the divergence

258 between other sister species (results not shown herein; see Puillandre et al., 2012;

259 Puillandre et al., 2017).

260

261 For these eight species hypotheses, we searched for all names available and potentially

262 applicable (see also the Taxonomy section). By consulting with the relevant literature 
on Turridae (e.g. Powell, 1964; Tucker, 2004) and by comparison of type specimens or their images to shells of sequenced specimens, we found 23 names (see Taxonomy section) that we applied tentatively to this partition. A total of 18 name-bearing types corresponding to 19 names were of sufficient quality to be included in the morphometric study. The other name-bearing types were discussed and assigned to molecular species using only the shell photographs or drawings and extrinsic parameters such as the bathymetry or geography (see Taxonomy section).

Despite considerable intraspecific morphological heterogeneity, the morphometric analysis yielded instructive results: using shape alone, the leave-one-out crossvalidation procedure successfully predicted correct species attribution of $84 \%$ of sequenced specimens and confirmed placement of 14 types out of 18 a priori attributed to our species hypotheses (see Figure S3). By adding shell size, we increased the score of the leave-one-out cross-validation procedure to $90.64 \%$ of the sequenced specimens, and 15 out of 18 types (Fig. 1). The three type specimens whose placement was incorrectly a priori attributed were Bathybermudia carynae (only representative of its species), Pleurotoma praesignis and Ptychosyrinx bisinuata japonica (see also taxonomic section). The most discriminant axis (Fig. 1, axis 1: $71.92 \%$ of trace) corresponds to the variation range of the siphonal canal length and the width of the shell, while variation along the second axis ( $15.57 \%$ of trace) mainly corresponds to the intensity of the curvature of the outer aperture lip.

The phylogenetic trees resulting from the COI (Fig. 2) and concatenated-gene analyses (Fig. 3) showed poorly supported interspecific relationships, except for the Cryptogemma phymatias/C. praesignis sister relationship and the (C. unilineata, $C$. timorensis, C. powelli) clade. Thus, the two molecular species PSH 11 and PSH 14 in 
287

288

289

290

291

292

293

294

295

296

297

298

299

300

301

302

303

304

305

306

307

308

309

310

the study of Puillandre et al. (2012), which were attributed to the genus Ptychosyrinx

Thiele, 1925, did not form a monophyletic group. The genera Cryptogemma Dall, 1918

(type species: Gemmula benthima Dall, 1908), Ptychosyrinx Thiele 1925 (type species:

Pleurotoma (Subulata) bisinuata Martens, 1901) and Pinguigemmula McNeil, 1961

(type species: Pinguigemmula okinavensis McNeil, 1960), despite being easily

recognizable morphologically, showed a level of molecular divergence among them that

was similar to, or even lower than, the level of divergence found among species in most

other turrid genera, thus suggesting synonymization of the two latter genera with

Cryptogemma.

All species showed large, oceanic or transoceanic, sympatric distributions. Despite

having large sympatric distribution, the $C$. phymatias/C. praesignis sister species are

found in different bathymetric zones, $\sim 1400-3000 \mathrm{~m}$ and $\sim 300-1400 \mathrm{~m}$ respectively,

with the exception of two specimens, one for each species, found at the same station

CP2752 (1378-1436 m) during the AURORA 2007 expedition, off Luzon Island, in

Philippines (see Table S1). All species geographic (Fig. 4) and depth (Fig. 5) ranges

were represented using only sequenced specimens, except for C. periscelida. For the

latter, the $C O I$ sequencing did not work for the $13 \mathrm{MNHN}$ samples available but

information on geography and bathymetry was included nonetheless.

\section{Abbreviations}

Museums and repositories

AMS: Australian Museum of Sydney, Sydney, Australia.

AWMM: Auckland War Memorial Museum, Auckland, New Zealand

BPBM: Bernice Pauahi Bishop Museum, Honolulu, USA. 
311 FMNH: Field Museum of Natural History, Chicago, USA.

312 MNHN: Muséum national d'Histoire naturelle, Paris, France.

313 NHMUK: Natural History Museum of United Kingdom, London, UK.

314 USNM: National Museum of Natural History, Smithsonian Institution, Washington, 315 DC, USA.

316 ZMB: Museum für Naturkunde, Humboldt-Universität, Berlin, Germany.

317 ZMMU: Zoological museum of Moscow University, Moscow, Russian Federation.

318 ZSIC: Zoological Survey of India, Calcutta, India.

319

320 Others

321 AL: Shell aperture length.

322 PD: Protoconch diameter.

323 PL: Protoconch length.

$324 \mathrm{R} / \mathrm{V}$ : research vessel.

325 St.: station.

Taxonomy

Superfamily Conoidea Fleming, 1822

330 Family Turridae H. \& A. Adams, 1853 (1838)

Genus Cryptogemma Dall, 1918

332

333 Type species: Gemmula benthima Dall, 1908 (OD)

334 Ptychosyrinx Thiele, 1925 (type species Pleurotoma bisinuata Martens, 1901 - OD) 
335

336

337

338

339

340

341

342

343

344

345

346

347

348

349

350

351

352

353

354

355

356

357

358

Bathybermudia Haas, 1949 (type species Bathybermudia carynae Haas, 1949 - OD)

$\uparrow$ Pinguigemmula McNeil, 1960 (type species $\uparrow$ Pinguigemmula okinavensis McNeil, $1960-$ OD)

Included species: Cryptogemma aethiopica (Thiele, 1925); C. periscelida (Dall, 1889);

C. phymatias (Watson, 1886); C. powelli sp. nov.; C. praesignis (Smith, 1895); C.

tessellata (Powell, 1964); C. timorensis (Tesch, 1915); C. unilineata (Powell, 1964).

Remarks: According to WoRMS (checked July 2019), Cryptogemma comprises 11

species, and has never been revised. A consultation of available type photos and published images on Cryptogemma species indicated that all of 11 species except the

type species $C$. benthima and $C$. phymatias, the senior synonym of $C$. benthima, should

be excluded from the genus, as the majority of them lack key characters such as the

narrow fusiform shell and the well-marked peripheral anal sinus. Moreover, studied

samples from Japan most certainly corresponding to the Cryptogemma corneus as

pictured in Hasegawa (2009: figs 335-338), showed closer affinity to other conoidean

families (e.g. Horaiclavidae) than to the Turridae, based on both, the sequence of the

barcode fragment of COI, and radular morphology (results not shown). The eight

species of Cryptogemma listed herein have wide distributions, most of them covering

the whole Indo-Pacific tropical region, and are not found at depths shallower than

$200 \mathrm{~m}$.

Protoconch consisting of 4 to 5.25 whorls. Shell shape of the teleoconch combined with

size is an important factor to distinguish species (see Results section), despite high

intra-specific variability. Widest variability range observed in shell proportions, with 
359 shells with wide last whorl and long siphonal canal being at one extreme of the range, 360 and more elongated shells with short siphonal canal on the other.

361

\section{Cryptogemma phymatias (Watson, 1886)}

363 (Fig. 6)

364

365

Pleurotoma phymatias R. B. Watson, 1886. 1920 m, Philippine Islands, $16^{\circ} 42 ' \mathrm{~N}$,

$119^{\circ} 22^{\prime}$ E (Expedition H.M.S. Challenger on November 13, 1874, st. 205).

Gemmula benthima Dall, 1908. 2323 m, Gulf of Panama.

Gemmula benthina - Dall, 1918: 318 (lapsus calami); Powell, 1964: 279 (lapsus calami).

Pleurotoma truncata Schepman, 1913. 2798 m, Banda Sea, Indonesia, 6²4'S, $124^{\circ} 39^{\prime} \mathrm{E}$.

Bathybermudia carynae Haas, 1949. 3109 m, off Bermuda, $32^{\circ} 08.2^{\prime} \mathrm{N}, 64^{\circ} 33^{\prime} \mathrm{W}$.

373

Remarks: This species was not present in the sampling of Puillandre et al. (2012) but was included in the phylogeny of Puillandre et al. (2011) under the name Ptychosyrinx carynae.

377 Due to the frequent loss of the shell apex, there are very few available protoconchs for 378 this species. Only the eroded protoconch of the type specimen of Bathybermudia 379 carynae could be measured, with $\mathrm{PD}=1.3 \mathrm{~mm}$ and $\mathrm{PL}>1.6 \mathrm{~mm}$, consisting of more 380 than 3 whorls.

381 Radula medium long, about $2.6 \mathrm{~mm}$ in length ( 0.44 of AL), composed of 74 transverse 382 rows of teeth. Marginal teeth 118-128 $\mu \mathrm{m}$ long (mean $120 \mu \mathrm{m}, \mathrm{n}=5$ ), duplex. Anterior 16 
383 (inner) $1 / 3$ of tooth length solid, very narrow in dorsal view, pointed, in posterior $2 / 3$ major and accessory limbs broadly bifurcating, accessory limb with clear constriction at about half tooth length, slightly shorter than major limb. Central formation with distinct narrow carinated cusp and lateral inconspicuous flaps with indistinct lateral and anterior margins (Fig. 7B-C).

Although this species can be distinguished from its congeners by the frequent loss of the first whorls, and from its sister species Cryptogemma praesignis by the slightly larger diameter of the shell, the bathymetry is its most distinct characteristic. C. praesignis is found between $\sim 300$ and $\sim 1400$ m depth, while Cryptogemma phymatias is the only Turridae to our knowledge to be exclusively found below $\sim 1400 \mathrm{~m}$ deep. Moreover, it is the only Turridae so far, and possibly the first reported benthic gastropod, to have a Pacific-Atlantic distribution (Fig. 4; see Discussion). Most studied type specimens have very eroded shells, but the variability of the last whorls, siphonal twist and aperture among them is in agreement with the variability in the sequenced specimens Noteworthily, the etymology of this species combines "Cryptogemma" (hidden gems) and "phymatias" (one who has tubercules), resulting in a confusing combination.

List of COI diagnostic sites (position: character state): [379: T, 493: C, 622: C].

Counting starts right next to the 3' end of the LCO1490 primer (from 1 to 658).

Distribution: From the Central Indo-Pacific (Banda Sea) to the North Atlantic Ocean (Bermuda Is.) (Fig. 4A), from $\sim 1400$ to $\sim 3000$ meters depth (Fig. 5). This species is expected to be found in the Indian Ocean, as is the case with other Indo-Pacific species 
406 of Cryptogemma, but it has not been documented there, due presumably to a lack of 407 sampling at bathyal depths.

408

\section{Cryptogemma praesignis (Smith, 1895)}

410 (Fig. 8A-K)

411

412

Pleurotoma praesignis Smith, 1895. 1234 m, off Colombo, Ceylon.

413

? Pleurotoma microscelida Dall, 1895. 642 m, South of Oahu Island Albatross st. 3475

414

Pleurotoma (Subulata) bisinuata Martens, 1901. 1134 m, off East Africa, 149'N, $45^{\circ} 29^{\prime} \mathrm{E}$.

416 Pleurotoma rotatilis Martens, 1902. 1134 m, off Mogadishu, Somalia, East Africa, 417 $1^{\circ} 49^{\prime} \mathrm{N}, 45^{\circ} 29^{\prime} \mathrm{E}$.

418

Pleurotoma (Surcula) lobata G. B. Sowerby III, 1903. 805 m, off Cape Natal, Durban

419

420

421

422

423

424

425

426

427

428

429 and 567 m, off Buffalo River, East London, S. Africa. E. A. Smith, 1906.

Ptychosyrinx bisinuata japonica Okutani, 1964. 620 m, Sea of Enshu-nada, Japan, $34^{\circ} 25.7^{\prime} \mathrm{N}, 137^{\circ} 58.5^{\prime} \mathrm{E}$.

Ptychosyrinx lordhoweensis Kantor \& Sysoev, 1991:205, figs. 1, 2. 1210 m, Lord Howe Rise, off eastern Australia, $30^{\circ} 24^{\prime} \mathrm{S}, 161^{\circ} 51^{\prime} \mathrm{E}$.

Remarks: This species corresponds to PSH 11 in Puillandre et al. (2012).

The protoconch exhibits a wide size range, with $\mathrm{PD}=1.05-1.38 \mathrm{~mm}$ and $\mathrm{PL}=1.4-1.93$ $\mathrm{mm}$, and from 4 to 5.2 whorls.

Radula long, about $3.4 \mathrm{~mm}$ in length ( 0.44 of AL), formed of 72 transverse rows of teeth. Marginal teeth $142-151 \mu \mathrm{m}$ long (mean $149 \mu \mathrm{m}, \mathrm{n}=5$, or $1.9 \%$ of AL), duplex. 
430 Anterior (inner) 1/3 of tooth length solid, narrow in dorsal view, pointed, in posterior

431
2/3 major and accessory limbs broadly bifurcating, accessory limb with clear

constriction and bent at about half tooth length, shorter than major limb. Central

formation with distinct narrow carinated cusp and lateral inconspicuous flaps with indistinct lateral and anterior margins (Fig. 7A).

This species is morphologically close to Cryptogemma timorensis, although it differs from that species in its generally smaller size $(\sim 15-35 \mathrm{~mm}$ SL), in having a narrower last whorl, and the presence of a tertiary apertural notch in mature females. Cryptogemma. praesignis also differs from $C$. timorensis in having a much longer radula (0.44 vs 0.2 of $\mathrm{AL})$ and relatively longer marginal teeth (1.9\% of AL vs $1.35 \%)$. Anatomical examination of Australian material (C571714 and C571704) shows that mature males (SL 29.4 and $34.9 \mathrm{~mm}$ respectively) can obtain an extremely large and muscular penis, with a width almost equal to the width of the animal itself, and with a very large, long lateral appendage situated distally. The penial tip is rather blunt, with the opening situated distally. A third, smaller Australian specimen (C571757; SL $25.7 \mathrm{~mm}$ ), did not possess a well-developed papilla, suggesting that such a feature may develop with increasing maturity and therefore not be present in subadults. Furthermore, the shells of C571714 and C571704 did not possess a tertiary apertural notch. The observation of C571714 and C571704 supplements the findings of Kantor \& Sysoev (1991) that the mature females of this species develop a tertiary apertural notch. The authors hypothesized that this structure was possibly connected with the process of fertilization. Such a feature has been observed in C. aethiopica specimens as well (Fig. 9G, I), but not in other Cryptogemma species. 
The general morphology, and more specifically the presence of a tertiary apertural notch in Pleurotoma bisinuata and Ptychosryinx bisinuata japonica, supports the synonymization of these names with C. praesignis. Because the holotype of P. bisinuata japonica is a comparatively large specimen $(39 \mathrm{~mm})$, the result of the LDA and the leave-one-out cross-validation procedure attributed it to C. timorensis. Possibly for this same reason, the holotype of $P$. praesignis $(42 \mathrm{~mm}$ ) also fell into the $C$. timorensis range. The result of the LDA analysis and the leave-one-out cross-validation procedure when considering only shape predicted the two holotypes as C. praesignis, (see Figure S3) thus justifying the attribution of $P$. praesignis to this molecular species. The sequencing of a paratype of $P$. lordhoweensis confirmed its conspecificity with $C$. praesignis. The name Pleurotoma lobata, although conchologically very similar to $P$. bisinuata, has never been synonymized based on the reportedly different morphology of the radula: the absence of a central tooth (= central formation as understood herein) in the specimens of $P$. lobata examined by Barnard (1958), contrasting with the large unicuspid rectangular-based central tooth described in P. bisinuata by Thiele (1929, p. 359). Powell (1964) suggested that Thiele could have mixed his radular preparations, but in light of the radulae type of Cryptogemma (Fig. 8), all composed of a unicuspid central formation, it is more likely that either it was Barnard, who mixed up the radula preparation, or that the specimens examined by Barnard are not Cryptogemma specimens. The holotype of Pleurotoma rotatilis is almost identical conchologically to a sequenced juvenile from the East African coast (MNHN-IM-2013-62900; Fig. 8J).

Some doubts remain as to the status of Pleurotoma microscelida, but the size and overall last whorl morphology of the type specimen show a stronger resemblance to $C$. praesignis than to any other Cryptogemma species. 
477

List of COI diagnostic sites (position: character state): [232: A, 319: T, 407: C, 409: T]

479

480

Distribution: This species is known to occur from the West Indian Ocean to the East

481

Pacific Ocean (Fig. 4B), from $\sim 300$ to $\sim 1400 \mathrm{~m}$ of depth (Fig. 5).

482

483

484

Cryptogemma timorensis (Tesch, 1915)

(Fig. 8L-P)

485

486

$\dagger$ Pleurotoma timorensis Tesch, 1915. Timor. Pliocene.

487

488

489

$†$ †leurotoma ktolemandoënsis K. Martin, 1933. Ktolemando. Miocene.

Ptychosyrinx timorensis teschi Powell, 1964: 291 (22-853), pl. 223, figs. 5, 6. 759 m, NW off Sipadan Island, Borneo.

490

491

Type locality: Pliocene of Timor Island.

492

493

494

Remarks: This species corresponds to PSH 14 of Puillandre et al. (2012).

Protoconch commonly eroded, with $\mathrm{PD}=1-1.2 \mathrm{~mm}$ and $\mathrm{PL}=1.3-1.675 \mathrm{~mm}$ and

495 number of whorls varying from 4 to 4.5 .

496 Radula medium short, about $2.5 \mathrm{~mm}$ in length ( 0.2 of $\mathrm{AL})$, formed of 45 transverse

497 rows of teeth. Marginal teeth $162-172 \mu \mathrm{m}$ long (mean $168 \mu \mathrm{m}, \mathrm{n}=5$, or $1.35 \%$ of $\mathrm{AL}$ ),

498 duplex. Anterior (inner) 1/3 of tooth length solid, medium broad in dorsal view,

499 lanceolate, in posterior $2 / 3$ major and accessory limbs broadly bifurcating, accessory

500 limb with clear constriction and bent at about half tooth length, nearly the same length 
501

502

503

504

505

506

507

508

509

510

511

512

513

514

515

516

517

as major limb. Central formation with short and obtuse cusp and lateral inconspicuous

flaps with indistinct lateral and anterior margins. Posterior margin thickened and

uninterrupted along its length (Fig. 7I).

This type of this species, Pleurotoma timorensis, is a fossil specimen from Timor island (Indonesia) described by Tesch, and Martin described another very similar specimen from Buton island (Indonesia), Pleurotoma ktolemandoënsis, without reference to the work of Tesch. However, Martin furtherly recognized the affinities between $P$. timorensis and P. ktolemandoënsis (Martin, 1935). Finally, Robba et al. (1989) synonymized P. ktolemandoënsis with P. timorensis. Powell (1964) described the subspecies Ptychosyrinx timorensis teschi based on an extant specimen, which Sysoev (1996) elevated to species rank. Both authors' arguments for separating the fossil species from the extant was the 'much broader' shell of the extant Ptychosyrinx timorensis teschi specimen. Examination of the morphological variability of the sequenced specimens showed that dimensions and shape of fossil specimens is close to the inferred average breadth of the species; some specimens show broader aperture and a taller last whorl than others, despite having the same number of teleochonch whorls. The results of the LDA showed that $P$. timorensis and $P$. timorensis teschi fall into the variability of the sequenced specimens. The broader last whorl and the generally larger size $(\sim 30-55 \mathrm{~mm})$ are characteristic for $C$. timorensis when compared to C. praesignis.

List of COI diagnostic sites (position: character state): [73: G, 214: G, 334: G, 511: G] 
523 Distribution: Found in the West Indian Ocean to the Central Indo-Pacific (Fig. 4C),

524 from $\sim 300$ to $\sim 1200$ meters depth (Fig. 5). Curiously, this species has not been found in

525 New-Caledonia, despite considerable sampling effort in this region.

526

527 Cryptogemma aethiopica (Thiele, 1925)

$528 \quad$ (Fig. 9)

529

530 Pleurotoma aethiopica Thiele, 1925.638 m, off Somalia, East Africa, $0^{\circ} 27 ' \mathrm{~S}$,

$53142^{\circ} 47.3^{\prime} E$. (Expedition Deutschen Tiefsee, st. 253).

532 Pleurotoma fusiformis Thiele, 1925:176(210), pl. 22(34), fig. 24. 614 m, Nias-südkanal, $533 \quad 0^{\circ} 15.2^{\prime} \mathrm{N}, 98^{\circ} 08.8^{\prime} \mathrm{E}$.

534 Gemmula thielei Finlay, 1930. (nom. nov. for Pleurotoma fusiformis Thiele, 1925).

$535 \dagger$ †leurotoma trincincta Martin, 1935:113, pl. 2, figs. 2, 2a. Buton Island, SE Celebes.

536 Oligocene.

$537 \uparrow$ Pinguigemmula okinavensis McNeil, 1960. Okinawa. Shinzato Tuff Member, Miocene 538 or Pliocene.

539 Pinguigemmula luzonica Powell, 1964 1964:278(22-790), pl. 215, figs. 3, 4. 326m, off

540 Hermana, Menor Island, Luzon Island, Philippines.

541 Pinguigemmula philippinensis Powell, 1964:278(22-790), pl. 215, figs. 5, 6. 512m, off 542 Santiago, west Luzon Island, Philippines.

544 Remarks: This species was not included in the study by Puillandre et al. (2012).

545 Protoconch commonly eroded, with $\mathrm{PD}=1.05-1.25, \mathrm{PL}=1.375-1.75$ and number of

546 whorls ranging from 4.2 to 5 . 
547 Radula long, about $3.4 \mathrm{~mm}$ in length ( 0.37 of AL), composed of 77 transverse rows of 548 teeth. Marginal teeth $150-159 \mu \mathrm{m}$ long (mean $155 \mu \mathrm{m}, \mathrm{n}=5$, or $1.66 \%$ of $\mathrm{AL}$ ), duplex.

549 Anterior (inner) 0.4 of tooth length solid, narrow in dorsal view, awl-shaped, in

550 posterior part major and accessory limbs broadly bifurcating, accessory limb with clear

551 constriction and bent at about half tooth length, thin, nearly same length as major limb.

552 Central formation with long, very narrow, sharp, carinated cusp and lateral flaps with

553 distinct posterior and antero-lateral margins. Flaps not completely fused with cusp (Fig.

$5547 \mathrm{E})$

555 The former Pinguigemmula genus is easily distinguishable from Gemmula in having a

556 broadly conic spire, a strongly constricted base and a long, straight siphonal canal

557 (Powell, 1964). Although expressing a wide variety of forms, the molecular analysis

558 resulted in a single species hypothesis. Several species were described based on the

559 sculptural details such as the number of gemmate cords (1, 2 or none). The sculpture

560 seems to correlate with geography, with the forms from West Indian Ocean having

561 smooth inter-suture sculpture, while the forms from East Indian-West Pacific usually

562 possess two or three gemmate cords. Some large specimens of this species possess a

563 similar 'tertiary notch' to that of $C$. praesignis, suggesting sexual dimorphism also for

564 this species (Kantor \& Sysoev, 1991).

565

566 List of COI diagnostic sites (position: character state): [115: C, 307: A, 418: G]

Distribution: Found in East Africa to Central Indo-Pacific (Fig. 4E), from $\sim 400$ to $\sim 850$ meters of depth (Fig. 5). 
571

572

573

574

575

576

577

578

579

580

581

582

583

584

585

586

587

588

589

590

591

592

593

594

\section{Cryptogemma tessellata (Powell, 1967)}

(Fig. 10A-D)

Gemmula tessellata Powell, 1967:439 (22-734a), pl. 315. 183-219m, off Waikiki, Oahu Island, Hawaiian Islands (Collected by Dr. Pat Burgess)

Remarks: This species corresponds to PSH 12 in Puillandre et al. (2012). The protoconch of the holotype is 4.5 whorls according to Powell (1967) and PD $=1.22 \mathrm{~mm}$ and $\mathrm{PL}=1.64 \mathrm{~mm}$ according to measurements inferred from photographs of the holotype. Protoconch with high variability, with $\mathrm{PD}=1.175-1.3, \mathrm{PL}=1.525-1.975$ and consisting of 4 to 5.5 whorls.

Radula medium long, about $1.2 \mathrm{~mm}$ in length ( 0.29 of AL), composed of 51 transverse rows of teeth. Marginal teeth $86-91 \mu \mathrm{m}$ long (mean $89 \mu \mathrm{m}, \mathrm{n}=2$, or $2.1 \%$ of AL), duplex. Anterior (inner) 1/2 of tooth length solid, medium broad in dorsal view, triangular, accessory limb weak, thin, without constriction, much shorter than major limb, but nearly of same width (the marginal teeth on Fig. 8F are not fully sclerotized). Central formation with long, sharp and carinated central cusp, slightly curved in profile, and with lateral conspicuous flaps with distinct margins. Flaps not completely fused with cusp. Anterior margin of central formation strongly concave (Fig. 7F).

The 'light form' of C. tessellata has been misidentified in Puillandre et al. (2012) as Xenuroturris gemmuloides Powell, 1967 as it shares superficially similar features such as the white-yellowish shell punctuated with regular brown-orange spots, and the small size ( $\sim 15-25 \mathrm{~mm})$. The ‘brown-orange form’ of $C$. tessellata, closer to the holotype, is quite different from the 'light form' not only in coloration, but also in having a stouter 
595 outline and a more tuberculate subsutural fold (Powell, 1964). Although readily

596 distinguished from the other Cryptogemma species due to its color pattern and small

597 size, LDA analysis indicates that this species more closely resembles small adults of $C$.

598 praesignis.

599

600 List of COI diagnostic sites (position: character state): [46: C, 61: A, 316: T]

601

602

Distribution: The sequenced specimens were found in New Caledonia only and the

holotype is from the Hawaiian Islands (Fig. 4C), from 200 to $\sim 500$ meters depth (Fig.

604

5). The protoconch characteristics, similar in shape, size and number of whorls to $C$.

605

praesignis, imply that the species may have a much broader range than what is currently

606

documented, possibly covering the entire Central Indo-Pacific.

607

608

Cryptogemma unilineata (Powell, 1967)

609 (Fig. 10E-H)

610

611

Gemmula congener unilineata Powell, 1967:437(22-716a), pl. 313. 366 m, off Waikiki,

612

Oahu Island, Hawaii (Expedition Pele, June 13 1964).

613

614

Remarks: This species corresponds to PSH 13 in Puillandre et al. (2012).

615 Protoconch commonly retained, with $\mathrm{PD}=1.075-1.275, \mathrm{PL}=1.375-1.925$ and number

616 of whorls ranging from 4.75 to 5.5 .

617 Radula long, about $3 \mathrm{~mm}$ in length ( 0.31 of AL), composed of 99 transverse rows of

618 teeth. Marginal teeth $121-127 \mu \mathrm{m}$ long (mean $125 \mu \mathrm{m}, \mathrm{n}=5$, or $1.27 \%$ of $\mathrm{AL}$ ), duplex. 
619 Anterior (inner) 0.4 of tooth length solid, very narrow in dorsal view, awl-shaped, in 620 posterior part major and accessory limbs broadly bifurcating, accessory limb with clear

622 formation with long sharp carinated cusp and lateral flaps with distinct posterior and 623 antero-lateral margins. Flaps not completely fused with cusp (Fig. 7G).

624 This species has been named based on the characteristic carinated brown-orange

625

640

641 642 subsutural band. The brown-orange subsutural band has been found in C. powelli $\mathrm{n}$. sp. and in some specimens of C. praesignis, as well as in other Turridae such as Gemmula cosmoi (Sykes, 1930), but it is generally smoother and thinner to that of C. unilineata. The LDA analysis indicated that $C$. unilineata has generally a more angulated shape on the outer aperture lip of the last whorl, indicating a more concave subsutural ramp in comparison to other Cryptogemma. However, we note that the convex hulls (Fig. 1) of C. unilineata and C. powelli sp. nov. are greatly overlapping, so the strong carinated brown-orange subsutural band remains the best suited character for distinguishing $C$. unlineata from C. powelli.

List of COI diagnostic sites (position: character state): [172: G, 307: T, 361: G, 370: C]

Distribution: From East Africa to Central Pacific (Hawaiian and Society islands) (Fig. 7D), from $\sim 300$ to $\sim 800$ meters of depth (Fig. 5).

\section{Cryptogemma periscelida (Dall, 1889)}

(Fig. 10I-K) 
Pleurotoma periscelida Dall, 1889. 283m (USS Albatross expedition, st. 2143, collected on March 23 1884) and (196m, off Hatteras, North Carolina)

646

647 Remarks:

648 The protoconch is unknown, as it is consistently eroded in all examined material, even 649 in younger specimens.

650 Radula medium long (part of youngest section lost), more than $1.9 \mathrm{~mm}$ in length $(>0.22$ 651 of AL), composed of more than 50 transverse rows of teeth. Marginal teeth $107-116 \mu \mathrm{m}$ 652 long (mean $110 \mu \mathrm{m}, \mathrm{n}=5$, or $1.25 \%$ of AL), duplex. Anterior (inner) 0.4 of tooth length 653 solid, narrow lanceolate in dorsal view, in posterior part major and accessory limbs 654 postero-lateral margins. Flaps completely fused with cusp (Fig. 7D). the Atlantic Ocean, and it occurs in a 200-800 m depth range.

662

List of COI diagnostic sites (position: character state): [352: C, 412: G, 655: C]

664

Distribution: Found in the Gulf of Mexico and further south to French Guyana (Fig.

666 4B), from $\sim 200$ to $\sim 500 \mathrm{~m}$ of depth (Fig. 5). 
667

668

669

670

671

672

673

674

675

676

677

678

679

680

681

682

683

684

685

686

\section{Cryptogemma powelli sp. nov.}

(Fig. 11)

Type material: Holotype MNHN-IM-2013-68787; Paratype 1, MNHN IM-2007-40795, paratype 2, MNHN-IM- 2007-40765, all live collected and processed for DNA extraction.

Type locality: New-Caledonia, South-West of Ile des Pins, $22^{\circ} 48^{\prime} \mathrm{S}, 167^{\circ} 15^{\prime} \mathrm{E}, 449-465$ meters depth, sand and debris (Expedition KANACONO, st. DW4697).

Etymology: Named after the New Zealand malacologist A.W.B. Powell (1901-1987), who contributed enormously to the systematics of Conoidea, and in particular, who revised the family Turridae in 1964 and described several species of Cryptogemma.

Description (holotype): Shell narrowly fusiform, with high spire, and medium-long siphonal canal. Protoconch conical, eroded, with a diameter of $1.125 \mathrm{~mm}$, of about 4 convex whorls. Teleoconch of 9 whorls; suture shallow, impressed. Shell height $38 \mathrm{~mm}$, aperture height $10.9 \mathrm{~mm}$ and shell diameter $12.5 \mathrm{~mm}$. Whorls strongly shouldered, with slightly concave shoulder slope, very weakly convex, nearly cylindrical periphery.

Spiral sculpture of fine, broadly spaced, wavy subequal spiral cords on subsutural ramp, 10 on last whorl, uppermost being much more pronounced than others, colored light orange-brown. Sinus cord strongly gemmate, with gemmules clearly bisected (39 on the body whorl). Spiral cords becoming thicker on whorl periphery, sometimes nodulose, 
691

692

some notably wider than others. Axial sculpture of fine growth lines. Last whorl shortly constricted to long siphonal canal, with 32 cords below sinus, of which about 20 on canal. Aperture irregular oval, outer lip thin, simple. Anal sinus moderately deep, Ushaped. Shell color straw-yellow, subsutural cord orange-brown, gemmae slightly lighter than background.

Radula medium long, around $3.1 \mathrm{~mm}$ in length ( 0.28 of $\mathrm{AL})$, composed of 75 transverse rows of teeth. Marginal teeth $129-135 \mu \mathrm{m}$ long (mean $133 \mu \mathrm{m}, \mathrm{n}=5$, or $1.22 \%$ of AL), duplex. Anterior (inner) 1/3 of tooth length solid, lanceolate in dorsal view, in posterior part major and accessory limbs broadly bifurcating, accessory limb with clear constriction at half tooth length, thin, about half length and width of major limb. Central formation with medium long and medium broad sharp carinated cusp and lateral flaps with distinct posterior and postero-lateral margins. Flaps not completely fused with cusp (Fig. 7H).

Remarks: This species corresponds to PSH 15 in Puillandre et al. (2012). Cryptogemma powelli sp. nov. exhibits similar intraspecific variation in shell shape to that of its congeners, based on its convex hull area (Fig. 1). Studied specimens vary in shades of shell color, from light yellowish to light orange, occasionally with a patchy pattern. In terms of both size and shape, $C$. powelli can in some cases be undistinguishable from $C$. unilineata (Fig. 1). The morphometric analysis shows considerable overlap of the measured shell features between the two species, with the main distinction between them expressed by the second axis. Interpretation of this result suggests that the $C$. powelli on average possess a more concave curvature of the outer aperture lip, compared to C. unilineata. Besides, distinction of C. powelli and C. unilineata mostly 
715

716

717

718

719

720

721

722

723

724

725

726

727

728

729

730

731

732

733

734

735

736

737

738

relies on the degree of pronunciation of the subsutural cord - it is typically not

significantly stronger than the succeeding cords in the former species, but is always

thick and gemmate in the latter. The subsutural cord is, however, thicker in younger

specimens, rendering the distinction of juvenile $C$. powelli and $C$. unilineata specimens problematic.

List of COI diagnostic sites (position: character state): [112: G, 322: T, 433: A]

Distribution: The confirmed distribution of this species based on sequenced specimens ranges from the Indian Ocean to the Central Indo-Pacific (Fig. 4F), from $\sim 400$ to $\sim 600 \mathrm{~m}$ of depth.

\section{Discussion}

Using an integrative taxonomy approach, by combining DNA-based species delimitation methods with classical morphological taxonomic methods, we reevaluated the Cryptogemma group studied in Puillandre et al. (2012) with new sequences - in some cases from type material - resulting in eight delimited species. Among the eight delimited species, C. phymatias, C. praesignis, C. timorensis and C. aethiopica comprise 20 of the available species names, with C. powelli the only one described as new. Our results contrast with the usual tendency in this family toward the discovery of new species (e.g. Puillandre et al., 2017; Abdelkrim et al., 2018b). All the synonymized species names in this group were established before the 'molecular era of taxonomy', reinforcing the recommendation - yet not always followed (Bouchet \& Strong, 2010) of systematically relying on molecular analysis, combined with other data, to delimit 
739

740

741

742

743

744

745

746

747

748

749

750

751

752

753

754

755

756

757

758

759

760

761

762

species. However, our study also shows that using only molecular delimitation of species while ignoring some key specimens such as types would limit knowledge of intra-specific morphological variability, thus obscuring also the ability to relate such variability to extrinsic parameters, such as geographic and bathymetric ranges. In this study, morphological study and taxonomic expertise on types resulted in the extension of intra-specific variability (Fig. 1; e.g. C. aethiopica types). This might be explained because, when describing a new species, there can be a strong subjective effect on the choice of the type specimens (usually the largest of a lot). The recent and promising success in sequencing DNA obtained from empty shells (Villanea et al., 2016;

Sarkissian et al., 2017) should assist in attributing names to molecularly-defined species by sequencing type specimens. However, sequencing shells implies destructive sampling, and will therefore possibly not be accepted by many museum curators. Furthermore, identifying and attributing material to species within a species complex still requires considerable taxonomic investigation.

By exploring the intraspecific variability of the shell, in isolation or in relation to interspecific variability, geographical and bathymetric ranges, or ecological data, we here emphasize a few remarks that may provide directions for the future study of this group.

Geographical intra-specific variability. In C. aethiopica, for which many species were synonymized, there are significant geographical variations in the spire whorls.

Specimens from the West Indian Ocean were found to have very smooth spire whorls, while specimens from the central Indo-Pacific were found with either two or three wellmarked gemmate cords. Considering the few available discrete shell features, these distinguishable characteristics were used by authors to justify the creation of several 
763

764

765

766

767

768

769

species names. No such intraspecific variation in shell sculpture was found in the other species of Cryptogemma, although other geographically-structured morphological variability has been observed in the Turridae genus Lophiotoma (Puillandre et al. 2017), with shell color varying from one side of the Indo-Pacific to the other.

Ecological variability. It is shown (e.g. Bierne et al., 2003; Hauquier et al., 2017) that some benthic species have clear preferences with regards to the substrate on which they thrive (e.g. sandy/muddy vs. rocky bottom). However, other species are generalists with respect to the substratum, as seems to be the case for the Cryptogemma species. All species were found both on hard and soft substrate, with or without organic matter (e.g. leaves or sunken wood). A remarkable case is $C$. tessellata, for which the three available trawl images showed three very different environments (Fig. 12), and, even more remarkably, correlated with shell morphology (Fig. 10C-D); specimens found in sandy or spongy environments exhibited a light pale color ground while the individual found in a volcanic rock bottom has a reddish color ground. However, the holotype of this species shows an intermediate pattern and was collected "in mud and sand" (Powell, 1964). More material is needed to properly study the potential effects of substrate on shell color.

Sexual dimorphism. C. praesignis is the first Turridae turrid species for which apparent sexual dimorphism of the shell has been documented (Kantor \& Sysoev, 1991). The (mature) females possess one or several tertiary notches that is probably linked to fertilization according to the authors, since mature males possess an extremely large and muscular penis. The authors proposed the hypothesis that these notches appear periodically during the breeding period, mainly based on the observation of several successive notches on the shells. 
Bathymetric zonation. Bathymetric segregation between sister species has been shown in molluscan species (e.g. Clague et al., 2012). In the Turridae, it has been found that a pair of sister species, Lophiotoma abbreviata and L. brevicaudata, show distinct bathymetric preferences, with the former observed at an average depth of $3 \mathrm{~m}$ and the latter at an average depth of $15 \mathrm{~m}$ (Puillandre et al., 2017). The present study demonstrates that, at a much wider scale, a similar case was found in the $C$. praesignis/C. phymatias species pair, with the former species occurring between $\sim 300$ to $\sim 1400 \mathrm{~m}$ and the latter between $\sim 1400$ to $\sim 3000 \mathrm{~m}$ depth (Fig. 5). This example could be added to the list of models used for studying speciation processes in benthic species with high dispersal capabilities and large geographic distributions, for which a topographic barrier would not satisfactorily explain genetic isolation (see Etter et al., 2005; Zardus et al., 2006).

Geographical ranges. While an Indo-Pacific distribution is common in benthic species, but so far no - molecularly supported - cases of Pacific-Atlantic distribution have been found in benthic gastropods. There are cases of cosmopolitan pelagic gastropods: Glaucus atlanticus (Churchill et al., 2014), Clione limacina (Jennings et al., 2010) and Fiona pinnata (Trickey et al., 2016). To this extent, C. phymatias could be the first documented, molecularly supported, case of a benthic gastropod with a Pacific-Atlantic distribution (Fig. 4A). Cases of such molecularly confirmed cosmopolitan benthic species have been found in other phyla such as Annelida (Meyer et al., 2008; Sun et al., 2016; Tomioka et al., 2016), Arthropoda (Casanova et al., 1998; Havermans et al., 2013) and Algae (Macaya \& Zuccarello, 2010). However, human-mediated introduction was strongly suggested for some of these cases, e.g. annelids. Nothing is known of the biological features of C. phymatias that would enable such a wide dispersal of larvae. 
811 Protoconch variability. As reported in Bouchet \& Warren (1979; 1994), many deep-

812

813

814 water gastropods' larval shells indicate a planktotrophic larval development, which is generally associated with good dispersal abilities and gene flow. The Cryptogemma species are no exception to this, with protoconch varying from 4 to 5.25 whorls. However, no correlation was found between the number of whorls of protoconch in a specimen and its associated depth, implying that, from a certain threshold (e.g. 4), the number of whorls is not the only factor determining the ability to disperse. Furthermore, in other neogastropod species complex for which there is a comparable number of protoconch whorls (e.g. Sanders et al., 2017) the study showed a strict ocean-delimited (e.g. Indian only, Pacific only) distribution. As for C. phymatias, the (eroded) protoconch of the holotype of B. carynae is to our knowledge the only one preserved (but slightly eroded) in this species, and it shows no major difference (diameter/height/number of whorls) from other Cryptogemma species with regards to this character that could explain its very large Pacific-Atlantic distribution.

Morphological stasis in teleoconch. C. praesignis and C. timorensis, previously assigned to Ptychosyrinx in Puillandre et al. (2012), show considerable similarity in shell sculpture despite not being sister species, and the two taxa would be difficult to distinguish without their significant difference in size. These two species represent a clear case of morphological homogeneity in Conoidea, for which other examples have been reported (Kantor et al., 2018). Large-scale morphometrics correlated with phylogeny may serve to better characterize and understand the conserved 'Gemmulalike' form across geological time. Some specimens from the Mio-Pliocene have been attributed to species of Cryptogemma (see 'Taxonomy'), however, an incommensurable number of 'Ptychosyrinx-like' or 'Gemmula-like' Turridae from the Paleogene will 
835

836

837

838

839

840

841

842

843

844

845

846

847

848

849

850

851

852

853

854

855

856

857

858

probably remain unattributed to a clade until a more comprehensive understanding, characterization and formalization of the family is achieved.

Radular morphology. The radula is an important morphological character in conoidean taxonomy. In Turridae, the radula is seemingly quite similar between congeneric species with few exceptions, such as for Iotyrris (Abdelkrim et al, 2018b). Cryptogemma presently is one of few genera of Turridae for which the radula has been examined for every representative species. Morphology of the marginal duplex teeth is rather similar among all species, except for slight variation in the development of the accessory limb; either shorter or nearly the same in length as the major limb (C. timorensis), or much narrower or nearly of the same width as the major limb (C. tesselata). However, we note this with the caveat that the shape of the duplex teeth as inferred from SEM images may differ considerably due to the position of the tooth, thus rendering comparison of different specimens and species imperfect. Additionally, there are large variations between species in the morphology of the central formation in terms of the shape of the central cusp and the degree of development and shape of the lateral flaps, in some cases with very distinct elevated edges (C. tesselata), in others with the flaps being barely distinguishable (Cryptogemma phymatias). Another potentially important character is the relative length of the radula, which may differ greatly between otherwise morphologically close species (e.g. C. praesignis and C. timorensis), number of transverse rows of teeth (in Cryptogemma varying from 45 to 99) and the relative length of the marginal teeth (from $1.22 \%$ of AL in C. powelli to $1.9 \%$ in C. praesignis). Unfortunately, little has been published on relative tooth size in different Turridae lineages and other groups of Conoidea to date. 
859 The above-mentioned characteristics of the Cryptogemma species have been revealed

860

861

862

863

864

865

866

867

868

869

870

871

872

873

874

875

876

877

878

879

880

881

by the morphological and molecular delimitation of species, a practice strongly advised

for future studies on the Turridae. In particular, it is shown here that morphological

differences associated with geographical or ecological diversity within the distribution

range of a species may lead to erroneous taxonomic conclusions. Unexpectedly wide

geographic distributions in particular, such as those documented herein, further add to

the challenges of conoidean taxonomy, notably where morphologically heterogenous

taxa are concerned. This is because material potentially seen as too widely separated

geographically to be considered relevant (or where geographically well-separated taxa

have not even been considered), may in fact represent conspecific material, a notion

supported by the numerous synonymizations herein. Combined with the fact that

sampling of the deep sea is infrequent and geographically severely incomplete

(potentially masking the presence of morphological clines which results in the over-

emphasis on few, morphologically discrete forms), future studies on deep-sea Conoidea

must take such wide distributions into account when embarking upon taxonomic

investigation.

Finally, the study of shell variability may serve to produce hypotheses regarding the

evolutionary processes that lead to such observed diversity. Indeed, the fact that the

actual, molecular-based Cryptogemma species were previously split by ante-molecular

taxonomists in several species each, has led us to a re-evaluation and re-interpretation of

the intraspecific morphological diversity that we could have neglected otherwise. In this

regard, the words of Darwin (1857) "It is good to have hair-splitters \& lumpers." make

sense: the splitter reminds lumpers that intraspecific variability should not be ignored, 
882

883

884

885

886

887

888

889

890

891

892

893

894

895

896

897

898

899

900

901

902

and the lumper reminds splitters that intraspecific variability should not be overinterpreted.

\section{References}

Abdelkrim J, Aznar-Cormano L, Buge B, Fedosov A, Kantor Y, Zaharias P, Puillandre

N. 2018a. Delimiting species of marine gastropods (Turridae, Conoidea) using RAD sequencing in an integrative taxonomy framework. Molecular Ecology 27: 4591-4611.

Abdelkrim J, Aznar-Cormano L, Fedosov AE, Kantor YI, Lozouet P, Phuong MA, Zaharias P, Puillandre N. 2018b. Exon-Capture-Based Phylogeny and Diversification of the Venomous Gastropods (Neogastropoda, Conoidea). Molecular Biology and Evolution 35: 2355-2374.

Barnard KH. 1958. Contribution to the knowledge of South African marine Mollusca.

Part 1. Gastropoda; Prosobranchiata: Toxoglossa. Annals of the South African Museum. Annale van die Suid-Afrikaanse Museum. 44: 73-163.

Bickford D, Lohman DJ, Sodhi NS, Ng PKL, Meier R, Winker K, Ingram KK, Das I. 2007. Cryptic species as a window on diversity and conservation. Trends in Ecology \& Evolution 22: 148-155.

Bierne N, Bonhomme F, David P. 2003. Habitat preference and the marine-speciation paradox. Proceedings of the Royal Society of London. Series B: Biological Sciences 270: 1399-1406. 
903 Bonhomme V, Picq S, Gaucherel C, Claude J. 2014. Momocs: outline analysis using R. 904 Journal of Statistical Software 56: 1-24.

905 Bouchet P, Kantor YI. 2004. New Caledonia: The major centre of biodiversity for 906 volutomitrid molluscs (Mollusca: Neogastropoda: Volutomitridae). Systematics and 907 Biodiversity 1: 467-502.

Bouchet P, Kantor YI, Sysoev A, Puillandre N. 2011. A new operational classification 909 of the Conoidea (Gastropoda). Journal of Molluscan Studies 77: 273-308.

Bouchet P, Strong E. 2010. Historical Name-Bearing Types in Marine Molluscs: An Impediment to Biodiversity Studies? In: Polaszek A, ed. Systema Naturae 250 - The Linnaean Ark. CRC Press, 63-74.

Bouchet P, Waren A. 1979. Planktotrophig larval development in deep-water gastropods. Sarsia 64: 37-40.

Bouchet P, Warén A. 1994. Ontogenetic migration and dispersal of deep-sea gastropod larvae. Reproduction, larval biology, and recruitment of the deep-sea benthos. Columbia University Press, New York: 98-118.

918 Bouckaert R, Vaughan TG, Barido-Sottani J, Duchêne S, Fourment M, Gavryushkina

919 A, Heled J, Jones G, Kühnert D, Maio ND, Matschiner M, Mendes FK, Müller NF, 920 Ogilvie HA, Plessis L du, Popinga A, Rambaut A, Rasmussen D, Siveroni I, Suchard 921 MA, Wu CH, Xie D, Zhang C, Stadler T, Drummond AJ. 2019. BEAST 2.5: An 922 advanced software platform for Bayesian evolutionary analysis. PLOS Computational 923 Biology 15: e1006650. 
924 Casanova JP, De Jong L, Faure E. 1998. Interrelationships of the two families

925

926

927

928

929

930

931

932

933

934

935

936

937

938

939

940

941

942

943

944

945

constituting the Lophogastrida (Crustacea: Mysidacea) inferred from morphological and molecular data. Marine Biology 132: 59-65.

Chan KO, Grismer LL, Brown RM. 2018. Comprehensive multi-locus phylogeny of

Old World tree frogs (Anura: Rhacophoridae) reveals taxonomic uncertainties and

potential cases of over- and underestimation of species diversity. Molecular

Phylogenetics and Evolution 127: 1010-1019.

Churchill CKC, Valdés Á, Foighil DÓ. 2014. Molecular and morphological systematics of neustonic nudibranchs (Mollusca : Gastropoda : Glaucidae : Glaucus), with descriptions of three new cryptic species. Invertebrate Systematics 28: 174-195.

Clague GE, Jones WJ, Paduan JB, Clague DA, Vrijenhoek RC. 2012. Phylogeography of Acesta clams from submarine seamounts and escarpments along the western margin of North America. Marine Ecology 33: 75-87.

Dall WH. 1918. Notes on the nomenclature of the mollusks of the family Turritidae. Proceedings of the United States National Museum, 54, 313-333.

Darwin Correspondence Project, “Letter no. 2130,” accessed on 31 July 2019, http://www.darwinproject.ac.uk/DCP-LETT-2130

Dayrat B. 2005. Towards integrative taxonomy. Biological Journal of the Linnean Society 85: 407-417.

Dayrat B, Tillier A, Lecointre G, Tillier S. 2001. New Clades of Euthyneuran Gastropods (Mollusca) from 28S rRNA Sequences. Molecular Phylogenetics and Evolution 19: 225-235. 
946 Dejaco T, Gassner M, Arthofer W, Schlick-Steiner BC, Steiner FM. 2016.

947 Taxonomist's Nightmare ... Evolutionist's Delight: An Integrative Approach Resolves

948 Species Limits in Jumping Bristletails Despite Widespread Hybridization and

949 Parthenogenesis. Systematic Biology 65: 947-974.

950 Edgar RC. 2004. MUSCLE: multiple sequence alignment with high accuracy and high 951 throughput. Nucleic Acids Research 32: 1792-1797.

952 Etter R, Rex MA, Chase MR, Quattro JM. 2005. Population Differentiation Decreases 953 with Depth in Deep-Sea Bivalves. Evolution 59: 1479-1491.

954 Fedosov AE, Puillandre N, Achaz, G. 2019. Revisiting use of DNA characters in 955 taxonomy with MolD-a tree independent algorithm to retrieve diagnostic nucleotide 956 characters from monolocus datasets. bioRxiv, 838151.

957 Fišer C, Robinson CT, Malard F. 2018. Cryptic species as a window into the paradigm 958 shift of the species concept. Molecular Ecology 27: 613-635.

959 Folmer O, Black M, Hoeh W, Lutz R, Vrijenhoek R. 1994. DNA primers for 960 amplification of mitochondrial cytochrome c oxidase subunit I from diverse metazoan 961 invertebrates. Molecular Marine Biology and Biotechnology: 6.

962 Galindo LA, Puillandre N, Strong EE, Bouchet P. 2014. Using microwaves to prepare 963 gastropods for DNA barcoding. Molecular Ecology Resources 14: 700-705.

964 Giardina CR, Kuhl FP. 1977. Accuracy of curve approximation by harmonically related 965 vectors with elliptical loci. Computer Graphics and Image Processing 6: 277-285. 
966 Hasegawa K. 2009. Upper bathyal gastropods of the Pacific coast of northern Honshu, 967 Japan, chiefly collected by R/V Wakataka-maru. Deep-sea fauna and pollutants off 968 Pacific coast of northern Japan. Natl. Mus. Nat. Sci. Monograph, 39, 225-383.

969 Hauquier F, Leliaert F, Rigaux A, Derycke S, Vanreusel A. 2017. Distinct genetic 970 differentiation and species diversification within two marine nematodes with different 971 habitat preference in Antarctic sediments. BMC Evolutionary Biology 17: 120.

972 Havermans C, Sonet G, d'Acoz C d’Udekem, Nagy ZT, Martin P, Brix S, Riehl T, 973 Agrawal S, Held C. 2013. Genetic and Morphological Divergences in the Cosmopolitan 974 Deep-Sea Amphipod Eurythenes gryllus Reveal a Diverse Abyss and a Bipolar Species. $975 \quad$ PLOS ONE 8: e74218.

976 Iglésias SP, Toulhoat L, Sellos DY. 2010. Taxonomic confusion and market 977 mislabelling of threatened skates: important consequences for their conservation status. 978 Aquatic Conservation: Marine and Freshwater Ecosystems 20: 319-333.

979 Jennings RM, Bucklin A, Ossenbrügger H, Hopcroft RR. 2010. Species diversity of 980 planktonic gastropods (Pteropoda and Heteropoda) from six ocean regions based on 981 DNA barcode analysis. Deep Sea Research Part II: Topical Studies in Oceanography $982 \quad 57: 2199-2210$.

983 Jovelin R, Justine JL. 2001. Phylogenetic relationships within the polyopisthocotylean 984 monogeneans (Platyhelminthes) inferred from partial $28 S$ rDNA sequences.

985 International Journal for Parasitology 31: 393-401.

986 Kabat AR. 1996. Molluscan types of the Albatross expeditions to the Eastern Pacific 987 described by WH Dall (1908): Bulletin of the Museum of Comparative Zoology. 
988 Kalyaanamoorthy S, Minh BQ, Wong TKF, von Haeseler A, Jermiin LS. 2017.

ModelFinder: fast model selection for accurate phylogenetic estimates. Nature Methods

990 14: $587-589$.

991

Kantor YI, Fedosov AE, Puillandre N. 2018. New and unusual deep-water Conoidea 992 revised with shell, radula and DNA characters. Ruthenica 28.

Kantor YI, Puillandre N. 2012. Evolution of the Radular Apparatus in Conoidea

(Gastropoda: Neogastropoda) as Inferred from a Molecular Phylogeny. Malacologia 55:

995 $55-90$.

996

Kantor YI, Sysoev AV. 1991. Sexual Dimorphism in the Apertural Notch of a New

997

Species of Gemmula (Gastropoda: Turridae). Journal of Molluscan Studies 57: 205-

998 209.

999

Kapli P, Lutteropp S, Zhang J, Kobert K, Pavlidis P, Stamatakis A, Flouri T. 2017.

1000

Multi-rate Poisson tree processes for single-locus species delimitation under maximum

1001 likelihood and Markov chain Monte Carlo. Bioinformatics 33: 1630-1638.

1002 Kumar S, Stecher G, Li M, Knyaz C, Tamura K. 2018. MEGA X: Molecular

1003 Evolutionary Genetics Analysis across Computing Platforms. Molecular Biology and

1004 Evolution 35: 1547-1549.

1005 Lefébure T, Douady CJ, Gouy M, Gibert J. 2006. Relationship between morphological

1006 taxonomy and molecular divergence within Crustacea: Proposal of a molecular

1007 threshold to help species delimitation. Molecular Phylogenetics and Evolution 40: 4351008447. 
1009 Macaya EC, Zuccarello GC. 2010. Dna Barcoding and Genetic Divergence in the Giant 1010 Kelp Macrocystis (laminariales)1. Journal of Phycology 46: 736-742.

1011 Martin K. 1935. Oligocaene Gastropoden von Buton. Rijksmuseum van Geologie en 1012 Mineralogie.

1013 Meyer A, Bleidorn C, Rouse GW, Hausen H. 2008. Morphological and molecular data 1014 suggest a cosmopolitan distribution of the polychaete Proscoloplos cygnochaetus Day, 10151954 (Annelida, Orbiniidae). Marine Biology 153: 879-889.

1016 Nguyen LT, Schmidt HA, von Haeseler A, Minh BQ. 2015. IQ-TREE: A Fast and 1017 Effective Stochastic Algorithm for Estimating Maximum-Likelihood Phylogenies. 1018 Molecular Biology and Evolution 32: 268-274.

1019 Pante E, Schoelinck C, Puillandre N. 2015. From Integrative Taxonomy to Species 1020 Description: One Step Beyond. Systematic Biology 64: 152-160.

1021 Powell AWB. 1964. The family Turridae in the Indo-Pacific. Part 1. The subfamily 1022 Turrinae. Indo-Pacific mollusca. 1: 227-346.

1023 Powell AWB. 1967. The family Turridae in the Indo-Pacific, Part 1a. The Turrinae 1024 concluded. Indo-Pacific mollusca. 1: 409-444

1025 Puillandre N, Cruaud C, Kantor YI. 2010. Cryptic species in Gemmuloborsonia 1026 (Gastropoda: Conoidea). Journal of Molluscan Studies 76: 11-23.

1027 Puillandre N, Fedosov AE, Zaharias P, Aznar-Cormano L, Kantor YI. 2017. A quest for 1028 the lost types of Lophiotoma (Gastropoda: Conoidea: Turridae): integrative taxonomy in 1029 a nomenclatural mess. Zoological Journal of the Linnean Society 181: 243-271. 
1030 Puillandre N, Kantor YI, Sysoev A, Couloux A, Meyer C, Rawlings T, Todd JA, 1031 Bouchet P. 2011. The dragon tamed? A molecular phylogeny of the Conoidea 1032 (Gastropoda). Journal of Molluscan Studies 77: 259-272.

1033 Puillandre N, Modica MV, Zhang Y, Sirovich L, Boisselier MC, Cruaud C, Holford M, 1034 Samadi S. 2012. Large-scale species delimitation method for hyperdiverse groups. 1035 Molecular Ecology 21: 2671-2691.

1036 Robba E, Sartono S, Violanti D, Erba E. 1989. Early Pleistocene gastropods from 1037 Timor. Memorie di Scienze Geologiche 41: 61-113.

1038 Ronquist F, Huelsenbeck JP. 2003. MrBayes 3: Bayesian phylogenetic inference under 1039 mixed models. Bioinformatics 19: 1572-1574.

1040 Sanders MT, Merle D, Bouchet P, Castelin M, Beu AG, Samadi S, Puillandre N. 2017. 1041 One for each ocean: revision of the Bursa granularis species complex (Gastropoda: 1042 Tonnoidea: Bursidae). Journal of Molluscan Studies 83: 384-398.

1043 Sarkissian CD, Pichereau V, Dupont C, Ilsøe PC, Perrigault M, Butler P, Chauvaud L, 1044 Eiríksson J, Scourse J, Paillard C, Orlando L. 2017. Ancient DNA analysis identifies 1045 marine mollusc shells as new metagenomic archives of the past. Molecular Ecology 1046 Resources 17: 835-853.

1047 Simon C, Franke A, Martin A. 1991. The Polymerase Chain Reaction: DNA Extraction 1048 and Amplification. In: Hewitt GM, In: Johnston AWB, In: Young JPW, eds. NATO 1049 ASI Series. Molecular Techniques in Taxonomy. Berlin, Heidelberg: Springer Berlin 1050 Heidelberg, 329-355. 
1051 Sun Y, Wong E, Tovar-Hernández MA, Williamson JE, Kupriyanova EK. 2016. Is 1052 Hydroides brachyacantha (Serpulidae : Annelida) a widespread species? Invertebrate 1053 Systematics 30: 41-59.

1054 Sysoev A. 1996. Deep-sea conoidean gastropods collected by the John Murray 1055 Expedition, 1933-34. Bulletin of the Natural History Museum. 62: 1-30.

1056 Thiele J. 1929. Handbuch der systematischen weichtierkunde. Jena: G. Fischer.

1057 Todd JA, Rawlings TA. 2014. A review of the Polystira clade — the Neotropic's largest 1058 marine gastropod radiation (Neogastropoda: Conoidea: Turridae sensu stricto ). Zootaxa 1059 3884: 445-491.

1060 Tomioka S, Kondoh T, Sato-Okoshi W, Ito K, Kakui K, Kajihara H. 2016.

1061 Cosmopolitan or Cryptic Species? A Case Study of Capitella teleta (Annelida:

1062 Capitellidae). Zoological Science 33: 545-554.

1063 Trickey JS, Thiel M, Waters JM. 2016. Transoceanic dispersal and cryptic diversity in a 1064 cosmopolitan rafting nudibranch. Invertebrate Systematics 30: 290-301.

1065 Tucker JK. 2004. Catalog of Recent and fossil turrids (Mollusca: Gastropoda). Zootaxa 1066 682: 1-1295.

1067 Villanea FA, Parent CE, Kemp BM. 2016. Reviving Galápagos snails: ancient DNA 1068 extraction and amplification from shells of probably extinct endemic land snails. 1069 Journal of Molluscan Studies 82: 449-456.

1070 Will KW, Mishler BD, Wheeler QD. 2005. The Perils of DNA Barcoding and the Need 1071 for Integrative Taxonomy. Systematic Biology 54: 844-851. 
1072 Zardus JD, Etter RJ, Chase MR, Rex MA, Boyle EE. 2006. Bathymetric and geographic 1073 population structure in the pan-Atlantic deep-sea bivalve Deminucula atacellana 1074 (Schenck, 1939). Molecular Ecology 15: 639-651.

1075

1076

1077 Legends

1078

1079 Figure 1: Projection of specimens along the two first discriminant axes. Convex hulls 1080 are drawn to easily observe the range of each species in the morphospace. Triangles are 1081 type specimens, with names of species indicated; the background color corresponds to 1082 the species attribution from the literature and the border color to the LDA prediction. 1083 Type specimens were not included in the LDA training set. Orange segments 1084 correspond to the projection of coefficients multiplied by the standard deviation of each 1085 raw variable (PC axes and shell length). Outlines of most extreme shapes are drawn 1086 with their respective MNHN numbers.

1087

1088 Figure 2: Bayesian Tree (MrBayes) for the COI. Posterior probabilities $(>0.95)$ are 1089 only shown for specific and inter-specific nodes. Abbreviations next to each specimen 1090 number refer to main marine provinces: WIP: Western Indo-Pacific; CIP: Central Indo1091 Pacific; EIP; Eastern Indo-Pacific; EP: Eastern Pacific; WA: Western Atlantic. 1092 Alignment provided in Appendix 1. 
1094 Figure 3: Bayesian Tree (MrBayes) of the COI, $12 S$ and $28 S$ concatenated. Posterior

1095

1096

1097

1098

1099

1100

1101

1102

1103

1104

1105

1106

1107

1108

1109

1110

1111

1112

1113

1114

1115

1116

probabilities and bootstrap values are shown for each node. Alignment provided in Appendix 2.

Figure 4: Map showing the species distributions. Filled circles represent localities of sequenced specimens; full triangles represent localities of type specimens.

Figure 5: Candlestick chart of depth distributions of the eight species. The high and low value correspond respectively to the minimum and maximum values of depth recorded for each species, while the open and close values correspond to the confirmed minimum and maximum values of depth. Confirmed minimum and maximum values of depth correspond respectively to the highest depth value of ending of trawl and the highest depth value of beginning of trawl.

Figure 6: Cryptogemma phymatias (Watson, 1886). (A) Lectotype of Gemmula benthima Dall, 1908, USNM 123089, Gulf of Panama. (B) Paralectotype of Gemmula benthima Dall, 1908, USNM 123087, Gulf of Panama. (C) Holotype of Bathybermudia carynae Haas, 1949, FMNH 31656, Bermuda. (D) Lateral view of the protoconch of $B$. carynae (E) Holotype of Pleurotoma phymatias Watson, 1886, NHMUK 1887.2.9.957, Philippines. (F-G) AMS T0077, IN2017_V03 - Sampling the Abyss, Jervis Commonwealth Marine Reserve. (H) MNHN-IM-2013-49928, R/V Tansei-maru, KT12-32, Okinawa. (I) MNHN-IM-2009-13476, AURORA 2007, Philippines. 
1117 Figure 7: Radulae of studied Cryptogemma. (A) Cryptogemma praesignis 1118 (Smith,1895). (B-C) Cryptogemma phymatias (Watson, 1886). (B) MNHN 1119 uncatalogued, Biocal, New-Caledonia, st. CP23 (C) USNM 857019, Venezuela. (D) 1120 Cryptogemma periscelida (Dall, 1889), R/V Pelican, $28^{\circ} 23.935^{\prime} \mathrm{N}, 8^{\circ} 22.508^{\prime} \mathrm{W}, 675-$ 1121765 m. (E) Cryptogemma aethiopica (Thiele, 1925), MNHN-IM-2013-50175, 1122 DONGSHA 2014, Taïwan. (F) Cryptogemma tessellata (Powell, 1964), MNHN-IM2007-40775, EBISCO, Chesterfield Islands. (G) Cryptogemma unilineata (Powell, 1124 1964), MNHN-IM-2013-61844, ZhongSha 2015, Taïwan. (H) Cryptogemma powelli sp. nov., MNHN-IM-2013-68787, KANACONO, New Caledonia. (I) Cryptogemma timorensis (Tesch, 1915), MNHN-IM-2013-09864, PAPUA NIUGINI, Papua. Scale 1127 bars $50 \mu \mathrm{m}$.

1128

Figure 8: (A-K) Cryptogemma praesignis (Smith,1895) and (L-P) Cryptogemma timorensis (Tesch, 1915). (A) Holotype of Pleurotoma praesignis Smith, 1895, ZSIC, Sri Lanka. (B) MNHN-IM-2009-13477, AURORA-2007, Philippines. (C) MNHN-IM2013-62903, BIOMAGLO, Iles Glorieuses. (D) Holotype of Pleurotoma lobata Sowerby III, 1903, NHMUK 1903.7.27.49, South Africa. (E) Holotype of Ptychosyrinx lordhoweensis, ZMMU Lc-14532, Lord Howe Rise. (F) Syntype of Pleurotoma bisinuata von Martens, 1901, ZMB 683, off East Africa. (G) Holotype of Pleurotoma microscelida Dall, 1895, USNM 127122, Hawaiian Islands. (H). Holotype of Pleurotoma rotatilis von Martens, 1902, ZMB 60070, off East Africa. (I) MNHN-IM2013-62893, BIOMAGLO, Iles Glorieuses. (J) MNHN-IM-2013-62900, BIOMAGLO, Iles Glorieuses. (K) Lateral view of the protoconch of MNHN-IM-2013-62893. (L)

1140 Holotype of Ptychosyrinx timorensis teschi Powell, 1964, USNM 239068, Borneo. (M) 
1141

1142

1143

1144

1145

1146

1147

1148

1149

1150

1151

1152

1153

1154

1155

1156

1157

1158

1159

1160

1161

1162

1163

1164

MNHN-IM-2009-14860, ATIMO VATAE, South of Madagascar. (N) MNHN-IM-

2007-40928, SALOMON 2, Salomon Islands. (O) MNHN-IM- 2013-58793,

KAVIENG, Papua. (P) Lateral view of the protoconch of MNHN-IM-2009-14935.

Figure 9: Cryptogemma aethiopica (Thiele, 1925). (A) Holotype of Pleurotoma aethiopica Thiele 1925, ZMB 109376, off East Africa. (B) Holotype of Pleurotoma fusiformis Thiele, 1925, ZMB 109388, off Sumatra. (C) MNH- IM-2009-14979, ATIMO VATAE, South of Madagascar. (D) Lateral view of the protoconch of MNHNIM-2013-48115, KANADEEP, Chesterfield Islands. (E) MNHN-IM- 2009-29301, EXBODI, New Caledonia. (F) MNHN-IM- 2009-14778, ATIMO VATAE, South of Madagascar. (G) Holotype of Pinguigemmula luzonica Powell, 1964, USNM 237784, Philippines. (H) Holotype of Pinguigemmula okinavensis McNeil, 1960, UNSM MO 562851, Miocene or Pliocene of Okinawa. (I) MNHN-IM-2013-19950, PAPUA NIUGINI, Papua. (J) Holotype of Pinguigemmula philippinensis Powell, 1964, USNM 237563, Philippines.

Figure 10: (A-D) Cryptogemma tessellata (Powell, 1964), (E-H) Cryptogemma unilineata (Powell, 1964) \& (I-K) Cryptogemma periscelida (Dall, 1889). (A) Holotype of Gemmula tessellata Powell, 1964, AWMM MA71042, Hawaiian Islands. (B) Lateral view of the protoconch of MNHN-IM-2013-48252, KANADEEP, Chesterfield Islands. (C) MNHN-IM-2009-24975, EXBODI, New Caledonia. (D) MNHN-IM- 2007-40775, EBSICO, Chesterfield Islands. (E) Holotype of Gemmula congener unilineata Powell, 1964, BPBM 8929, Hawaiian Islands. (F) Lateral view of the protoconch of MNHN- 
1165 IM-2007-40786, NORFOLK 2, New Caledonia. (G) MNHN-IM-2009-14953, ATIMO

1166 VATAE, South of Madagascar. (H) MNHN-IM-2007-38340, MAINBAZA, Mozambic 1167 channel. (I) Lectotype of Pleurotoma periscelida Dall, 1889, USNM 87391, Columbia. 1168 (J) MNHN-IM- 2013-56285, GUYANE 2014, French Guyana. (K) MNHN-IM- 20131169 56283, GUYANE 2014, French Guyana.

1170

1171

1172

1173

1174

MNHN-IM- 2007-40765, EBISCO, Chesterfield Islands. (E) Paratype 2, MNHN-IM-

1175

2007-40795, Norfolk 2, New Caledonia. (F) MNHN-IM-2013-55832, TAIWAN 2013,

1176

Taïwan. (G-I) Paratype, MNHN-IM- 2007-40765, EBISCO, Chesterfield Islands.

1177

1178

Figure 12: Pictures of trawls from stations were Cryptogemma tessellata (Powel, 1964)

1179 specimens were found.

1180

1181

1182

Supplementary Material

1183

1184

Figure S1: Result of the leave-one-out cross-validation procedure that was used to find

1185 the number of PC axes leading to the best percentage of species predictions.

1186

1187 Figure S2: Results of the ABGD, mPTP and GMYC analysis

1188 
1189 Figure S3: Results of the morphometric analysis without taking size in account.

1190

1191 Table S1: Material examined in this study 


.

(1)
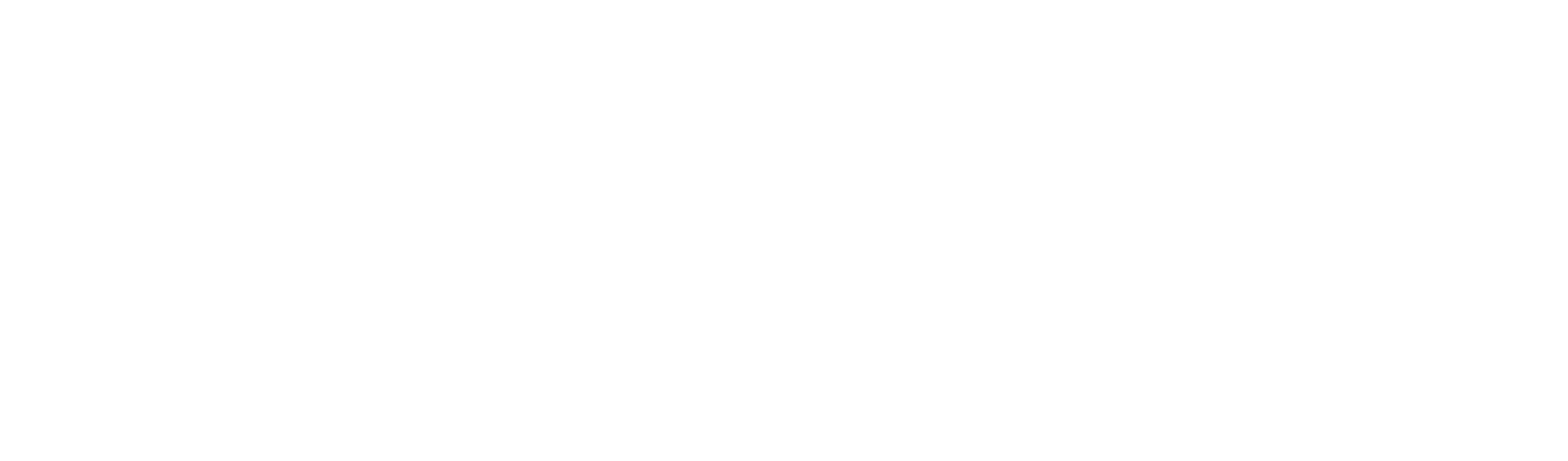


\title{
Unable to Convert Image
}

\author{
The dimensions of this image (in pixels) are too large \\ to be converted. For this image to convert, \\ the total number of pixels (height $x$ width) must be \\ less than 40,000,000 (40 megapixels).
}

\begin{abstract}
Projection of specimens along the two first discriminant axes. Convex hulls are drawn to easily observe the range of each species in the morphospace. Triangles are type specimens, with names of species indicated; the background color corresponds to the species attribution from the literature and the border color to the LDA prediction. Type specimens were not included in the LDA training set. Orange segments correspond to the projection of coefficients multiplied by the standard deviation of each raw variable (PC axes and shell length). Outlines of most extreme shapes are drawn with their respective MNHN numbers.
\end{abstract}




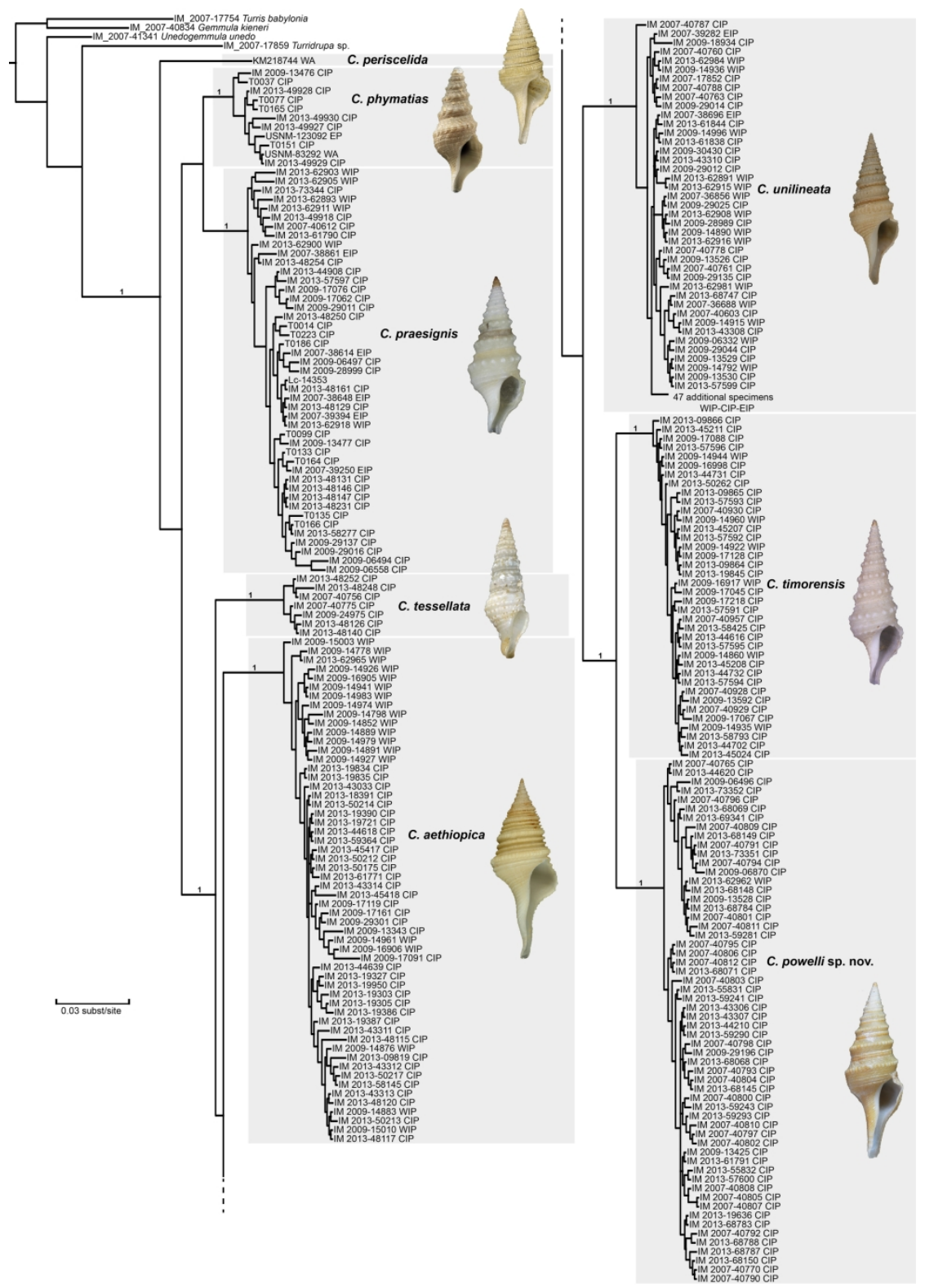

Bayesian Tree (MrBayes) for the COI. Posterior probabilities (>0.95) are only shown for specific and interspecific nodes. Abbreviations next to each specimen number refer to main marine provinces: WIP: Western Indo-Pacific; CIP: Central Indo-Pacific; EIP; Eastern Indo-Pacific; EP: Eastern Pacific; WA: Western Atlantic. Alignment provided in Appendix 1.

$205 \times 289 \mathrm{~mm}(300 \times 300$ DPI) 
Bayesian Tree (MrBayes) of the COI, 12S and 28S concatenated. Posterior probabilities and bootstrap values are shown for each node. Alignment provided in Appendix 2.

\section{$155 \times 79 \mathrm{~mm}(300 \times 300 \mathrm{DPI})$}




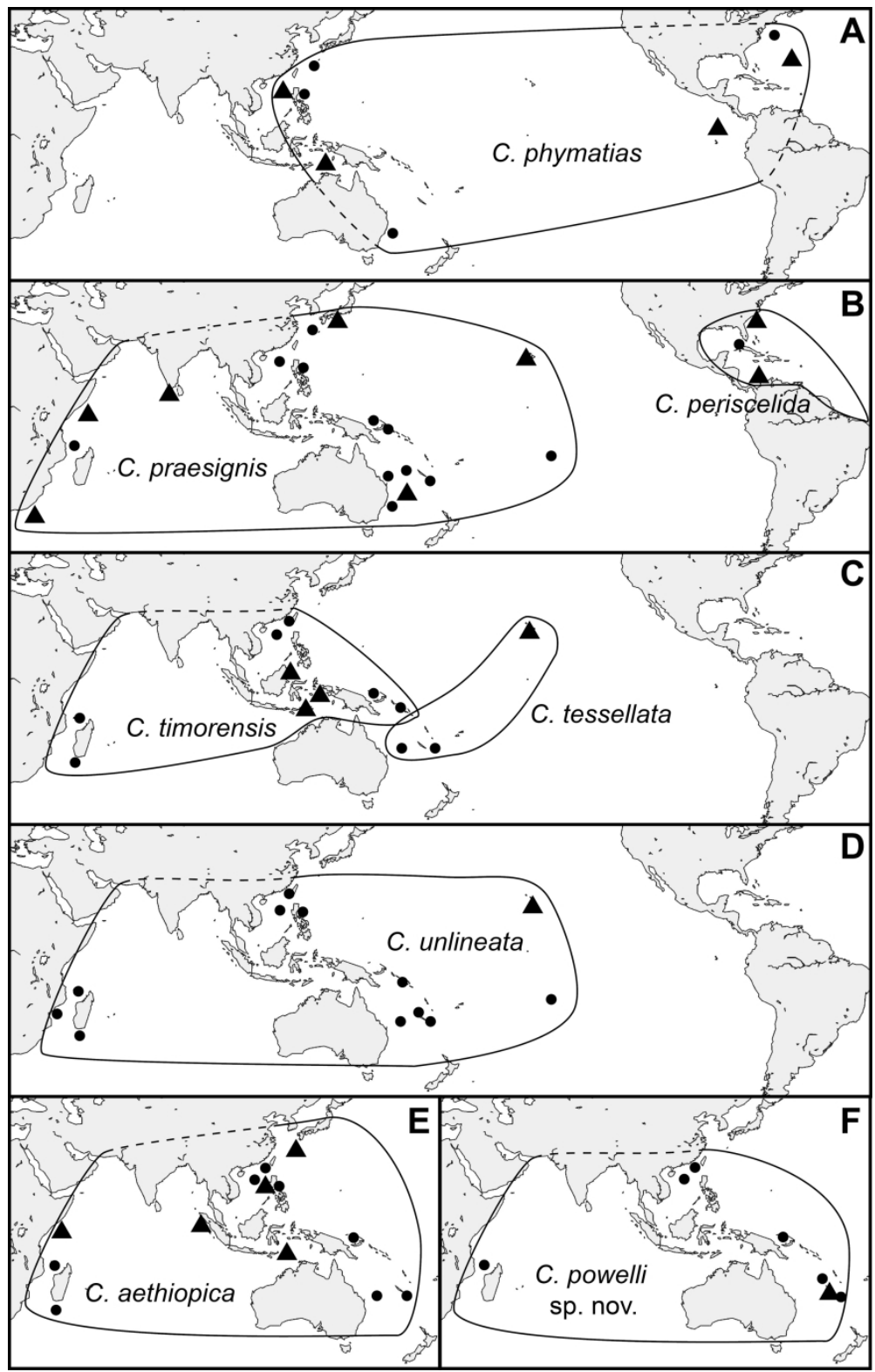

Map showing the species distributions. Filled circles represent localities of sequenced specimens; full triangles represent localities of type specimens.

$188 \times 297 \mathrm{~mm}(300 \times 300 \mathrm{DPI})$ 
C. aethiopica C. timorensis

C. praesignis C.phymatias
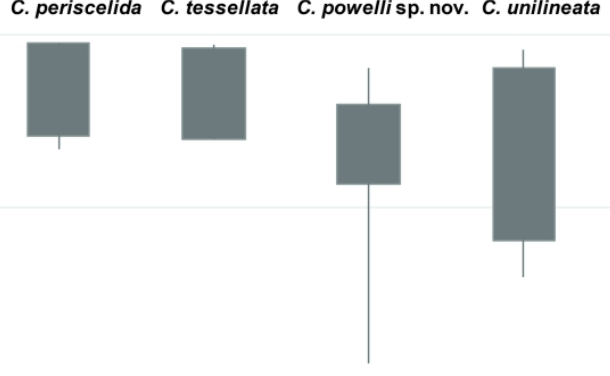

C. aethiopica

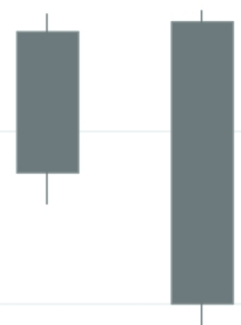

200

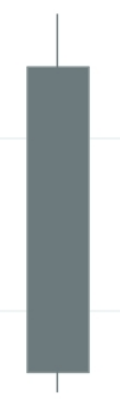

700
1200

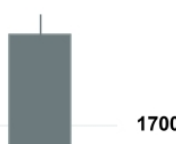

2200

2700

3200

Candlestick chart of depth distributions of the eight species. The high and low value correspond respectively to the minimum and maximum values of depth recorded for each species, while the open and close values correspond to the confirmed minimum and maximum values of depth. Confirmed minimum and maximum values of depth correspond respectively to the highest depth value of ending of trawl and the highest depth value of beginning of trawl.

$276 \times 230 \mathrm{~mm}(300 \times 300$ DPI $)$ 


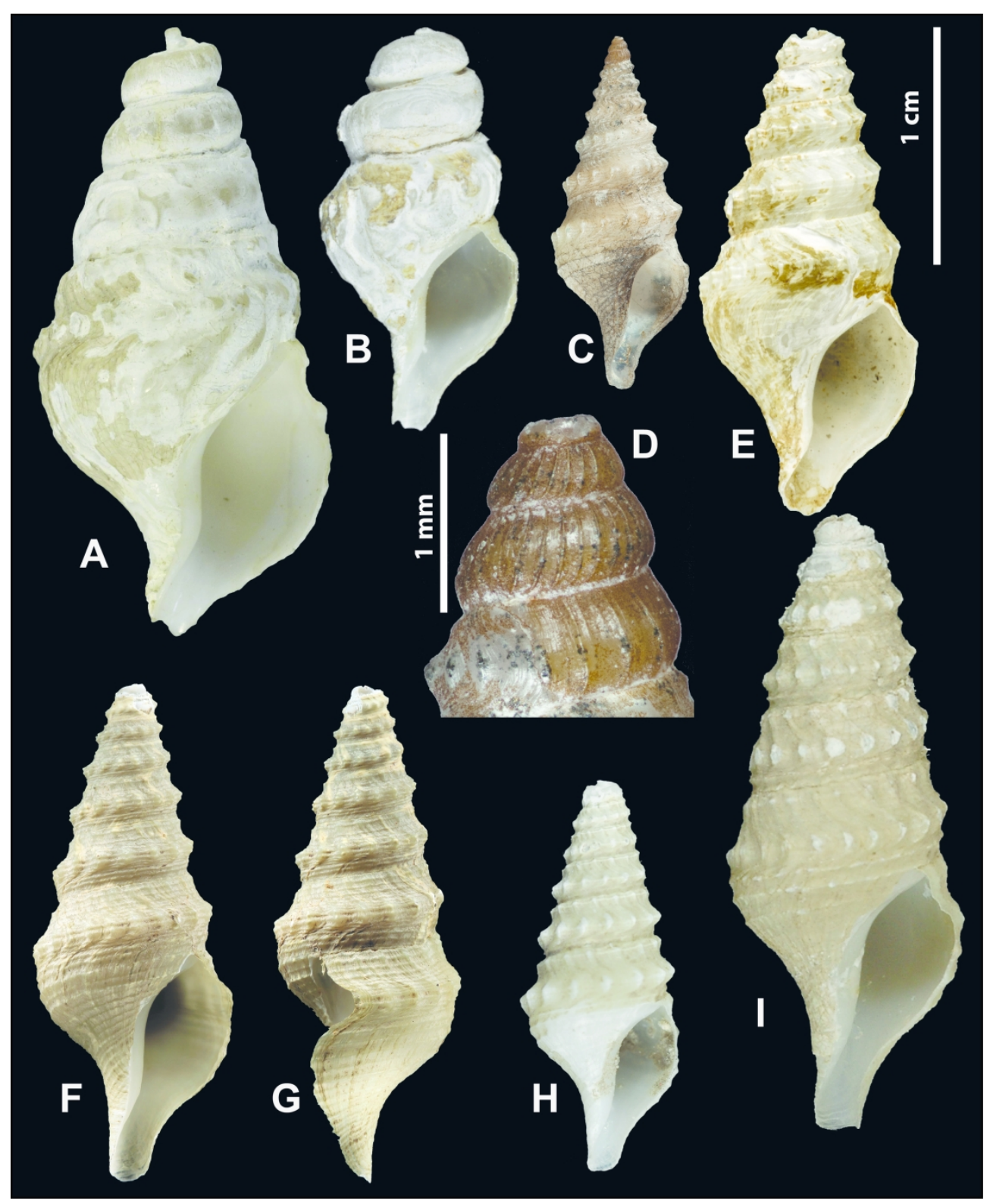

Cryptogemma phymatias (Watson, 1886). (A) Lectotype of Gemmula benthima Dall, 1908, USNM 123089, Gulf of Panama. (B) Paralectotype of Gemmula benthima Dall, 1908, USNM 123087, Gulf of Panama. (C) Holotype of Bathybermudia carynae Haas, 1949, FMNH 31656, Bermuda. (D) Lateral view of the protoconch of $B$. carynae (E) Holotype of Pleurotoma phymatias Watson, 1886, NHMUK 1887.2.9.957, Philippines. (F-G) AMS T0077, IN2017_V03 - Sampling the Abyss, Jervis Commonwealth Marine Reserve. (H) MNHN-IM-201349928, R/V Tansei-maru, KT-12-32, Okinawa. (I) MNHN-IM-2009-13476, AURORA 2007, Philippines. 

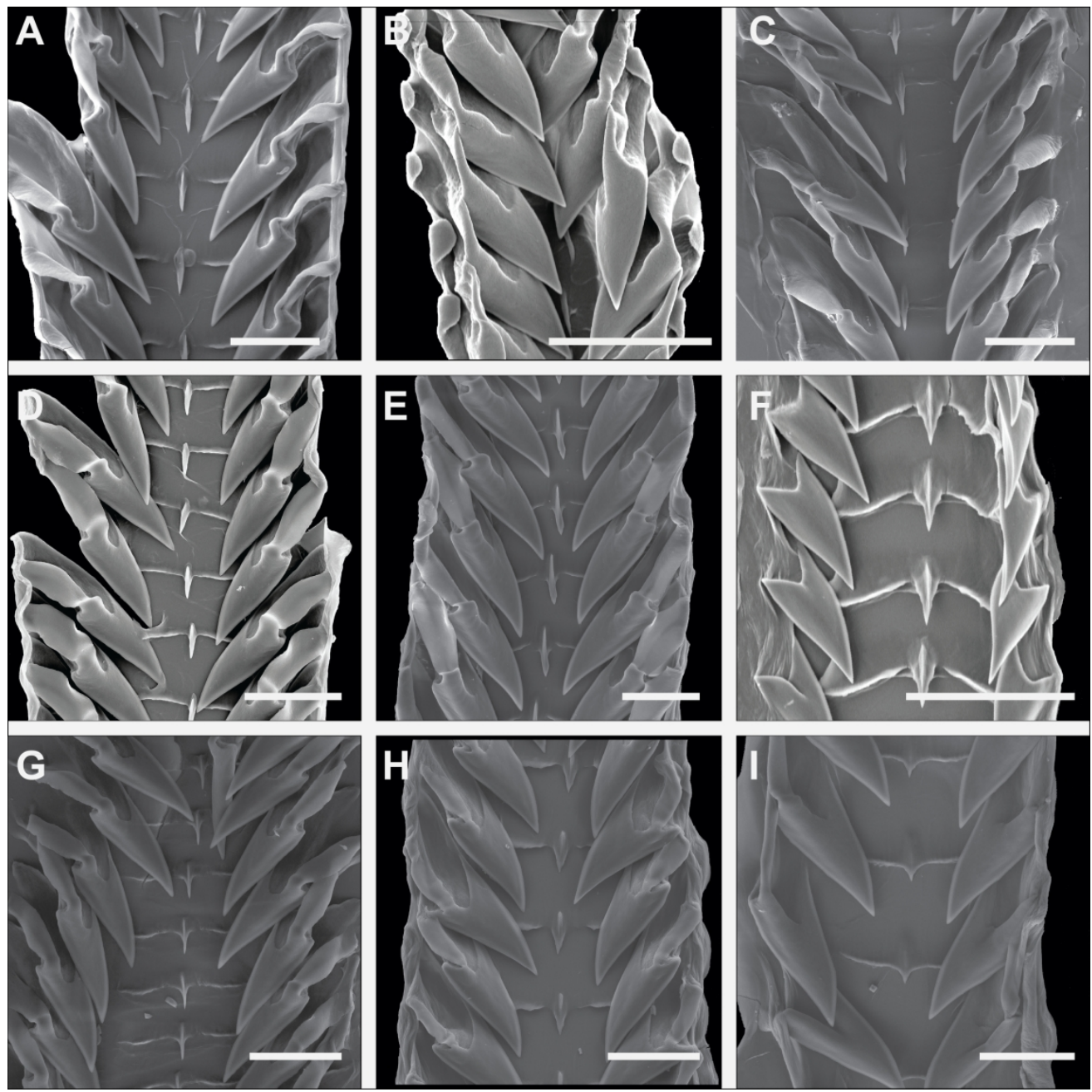

Radulae of studied Cryptogemma. (A) Cryptogemma praesignis (Smith,1895). (B-C) Cryptogemma phymatias (Watson, 1886). (B) MNHN uncatalogued, Biocal, New-Caledonia, st. CP23 (C) USNM 857019, Venezuela. (D) Cryptogemma periscelida (Dall, 1889), R/V Pelican, $28^{\circ} 23.935^{\prime} \mathrm{N}, 8^{\circ} 22.508^{\prime} \mathrm{W}, 675-765 \mathrm{~m}$.

(E) Cryptogemma aethiopica (Thiele, 1925), MNHN-IM-2013-50175, DONGSHA 2014, Taïwan. (F)

Cryptogemma tessellata (Powell, 1964), MNHN-IM-2007-40775, EBISCO, Chesterfield Islands. (G) Cryptogemma unilineata (Powell, 1964), MNHN-IM-2013-61844, ZhongSha 2015, Taïwan. (H) Cryptogemma powelli sp. nov., MNHN-IM-2013-68787, KANACONO, New Caledonia. (I) Cryptogemma timorensis (Tesch, 1915), MNHN-IM-2013-09864, PAPUA NIUGINI, Papua. Scale bars $50 \mu \mathrm{m}$. 


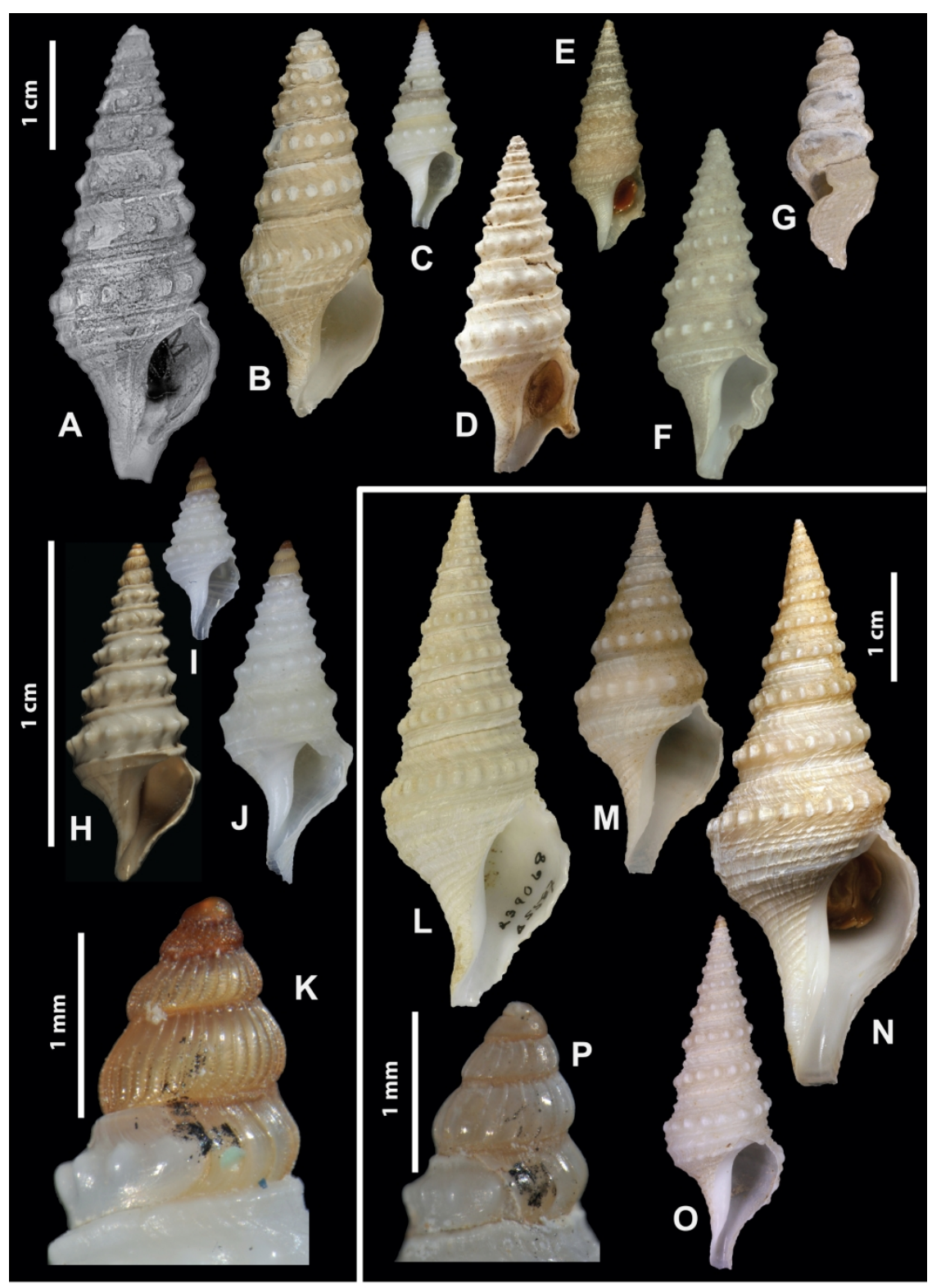

(A-K) Cryptogemma praesignis (Smith,1895) and (L-P) Cryptogemma timorensis (Tesch, 1915). (A) Holotype of Pleurotoma praesignis Smith, 1895, ZSIC, Sri Lanka. (B) MNHN-IM-2009-13477, AURORA-2007, Philippines. (C) MNHN-IM-2013-62903, BIOMAGLO, Iles Glorieuses. (D) Holotype of Pleurotoma lobata Sowerby III, 1903, NHMUK 1903.7.27.49, South Africa. (E) Holotype of Ptychosyrinx lordhoweensis, ZMMU LC-14532, Lord Howe Rise. (F) Syntype of Pleurotoma bisinuata von Martens, 1901, ZMB 683, off East Africa. (G) Holotype of Pleurotoma microscelida Dall, 1895, USNM 127122, Hawaiian Islands. (H). Holotype of Pleurotoma rotatilis von Martens, 1902, ZMB 60070, off East Africa. (I) MNHN-IM-2013-62893, BIOMAGLO, Iles Glorieuses. (J) MNHN-IM-2013-62900, BIOMAGLO, Iles Glorieuses. (K) Lateral view of the protoconch of MNHN-IM-2013-62893. (L) Holotype of Ptychosyrinx timorensis teschi Powell, 1964, USNM 239068, Borneo. (M) MNHN-IM-2009-14860, ATIMO VATAE, South of Madagascar. (N) MNHN-IM- 200740928, SALOMON 2, Salomon Islands. (O) MNHN-IM- 2013-58793, KAVIENG, Papua. (P) Lateral view of the protoconch of MNHN-IM-2009-14935. 


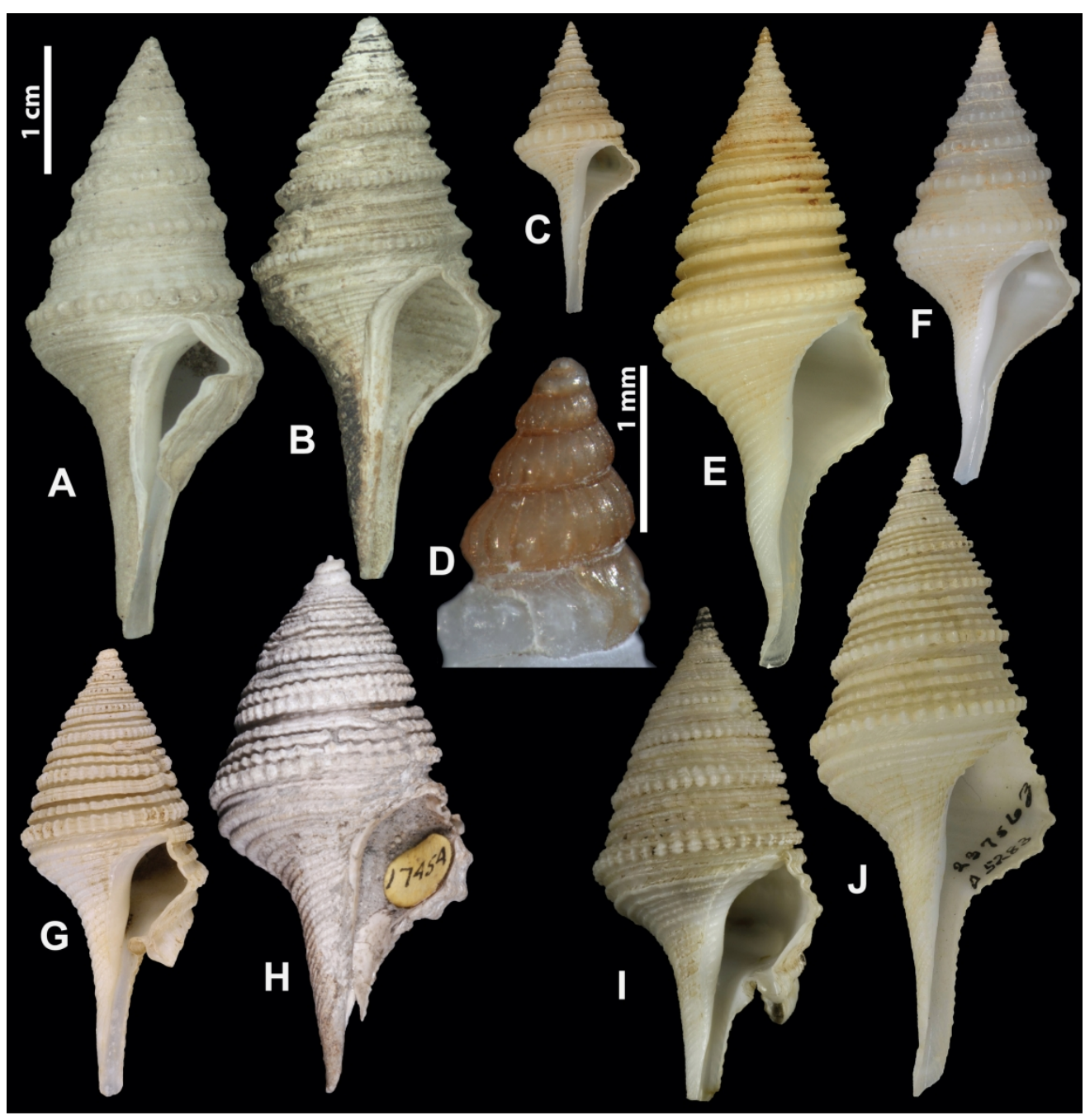

Cryptogemma aethiopica (Thiele, 1925). (A) Holotype of Pleurotoma aethiopica Thiele 1925, ZMB 109376, off East Africa. (B) Holotype of Pleurotoma fusiformis Thiele, 1925, ZMB 109388, off Sumatra. (C) MNH- IM2009-14979, ATIMO VATAE, South of Madagascar. (D) Lateral view of the protoconch of MNHN-IM-201348115, KANADEEP, Chesterfield Islands. (E) MNHN-IM- 2009-29301, EXBODI, New Caledonia. (F) MNHN-IM2009-14778, ATIMO VATAE, South of Madagascar. (G) Holotype of Pinguigemmula luzonica Powell, 1964, USNM 237784, Philippines. (H) Holotype of Pinguigemmula okinavensis McNeil, 1960, UNSM MO 562851, Miocene or Pliocene of Okinawa. (I) MNHN-IM-2013-19950, PAPUA NIUGINI, Papua. (J) Holotype of Pinguigemmula philippinensis Powell, 1964, USNM 237563, Philippines. 


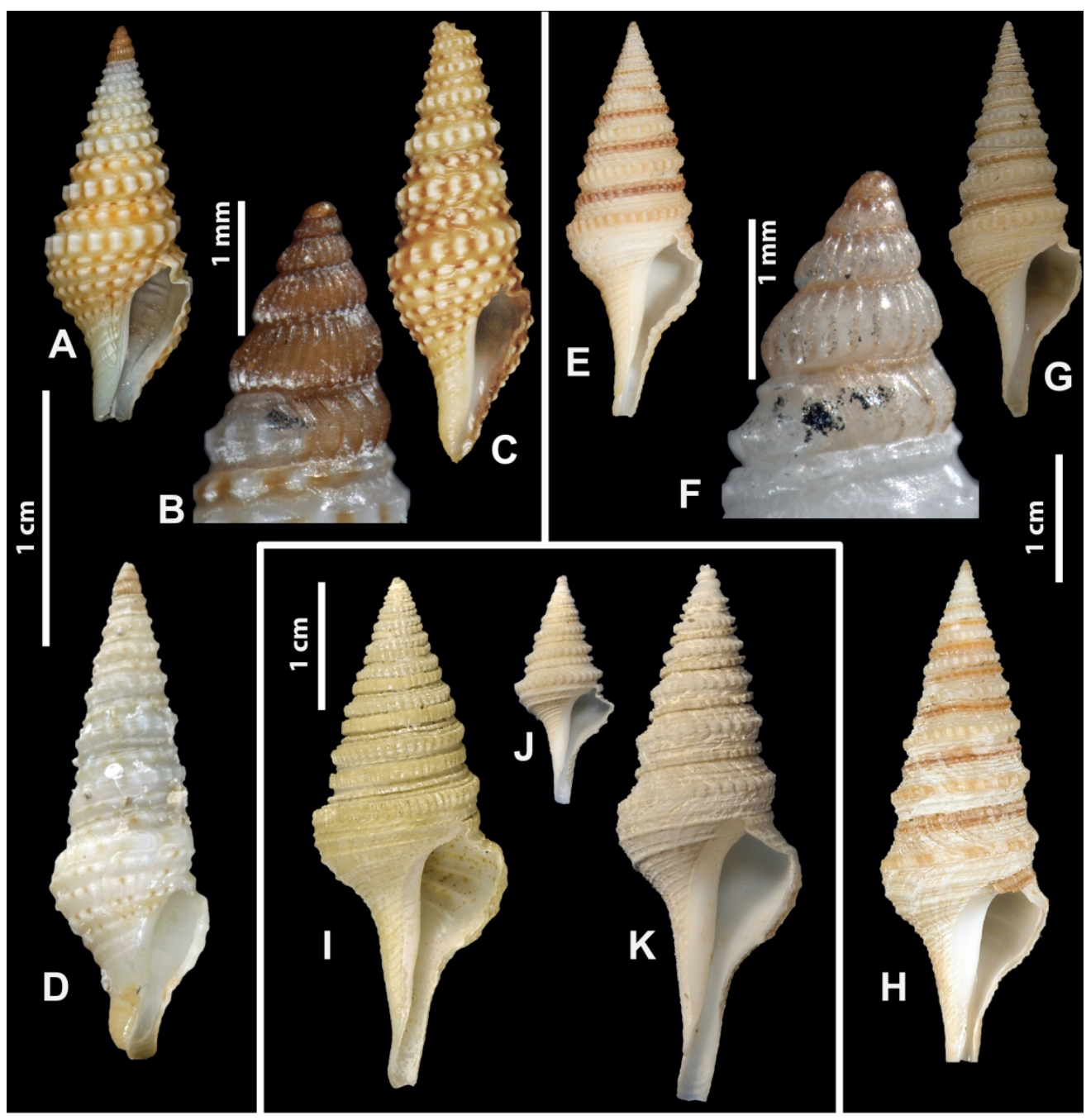

(A-D) Cryptogemma tessellata (Powell, 1964), (E-H) Cryptogemma unilineata (Powell, 1964) \& (I-K) Cryptogemma periscelida (Dall, 1889). (A) Holotype of Gemmula tessellata Powell, 1964, AWMM MA71042, Hawaiian Islands. (B) Lateral view of the protoconch of MNHN-IM-2013-48252, KANADEEP, Chesterfield Islands. (C) MNHN-IM-2009-24975, EXBODI, New Caledonia. (D) MNHN-IM- 2007-40775, EBSICO, Chesterfield Islands. (E) Holotype of Gemmula congener unilineata Powell, 1964, BPBM 8929, Hawaiian Islands. (F) Lateral view of the protoconch of MNHN-IM-2007-40786, NORFOLK 2, New Caledonia. (G) MNHN-IM-2009-14953, ATIMO VATAE, South of Madagascar. (H) MNHN-IM-2007-38340, MAINBAZA, Mozambic channel. (I) Lectotype of Pleurotoma periscelida Dall, 1889, USNM 87391, Columbia. (J) MNHNIM- 2013-56285, GUYANE 2014, French Guyana. (K) MNHN-IM- 2013-56283, GUYANE 2014, French Guyana. 


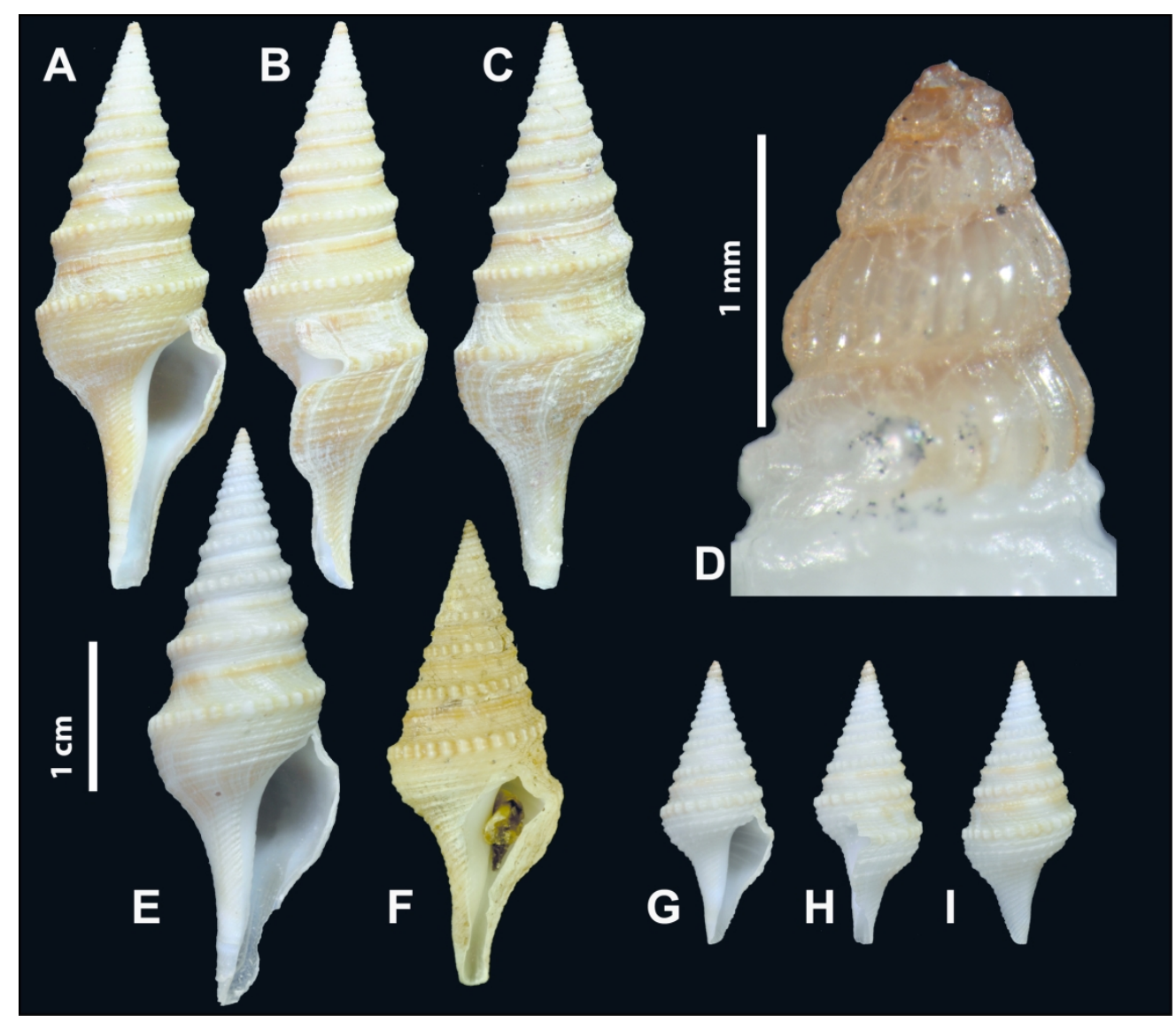

Cryptogemma powelli sp. nov. (A-C) Holotype, MNHN-IM- 2013-68787, KANACONO, New Caledonia. (D) Lateral view of the protoconch of the paratype 1 MNHN-IM- 2007-40765, EBISCO, Chesterfield Islands. (E) Paratype 2, MNHN-IM-2007-40795, Norfolk 2, New Caledonia. (F) MNHN-IM-2013-55832, TAIWAN 2013, Taïwan. (G-I) Paratype, MNHN-IM- 2007-40765, EBISCO, Chesterfield Islands. 

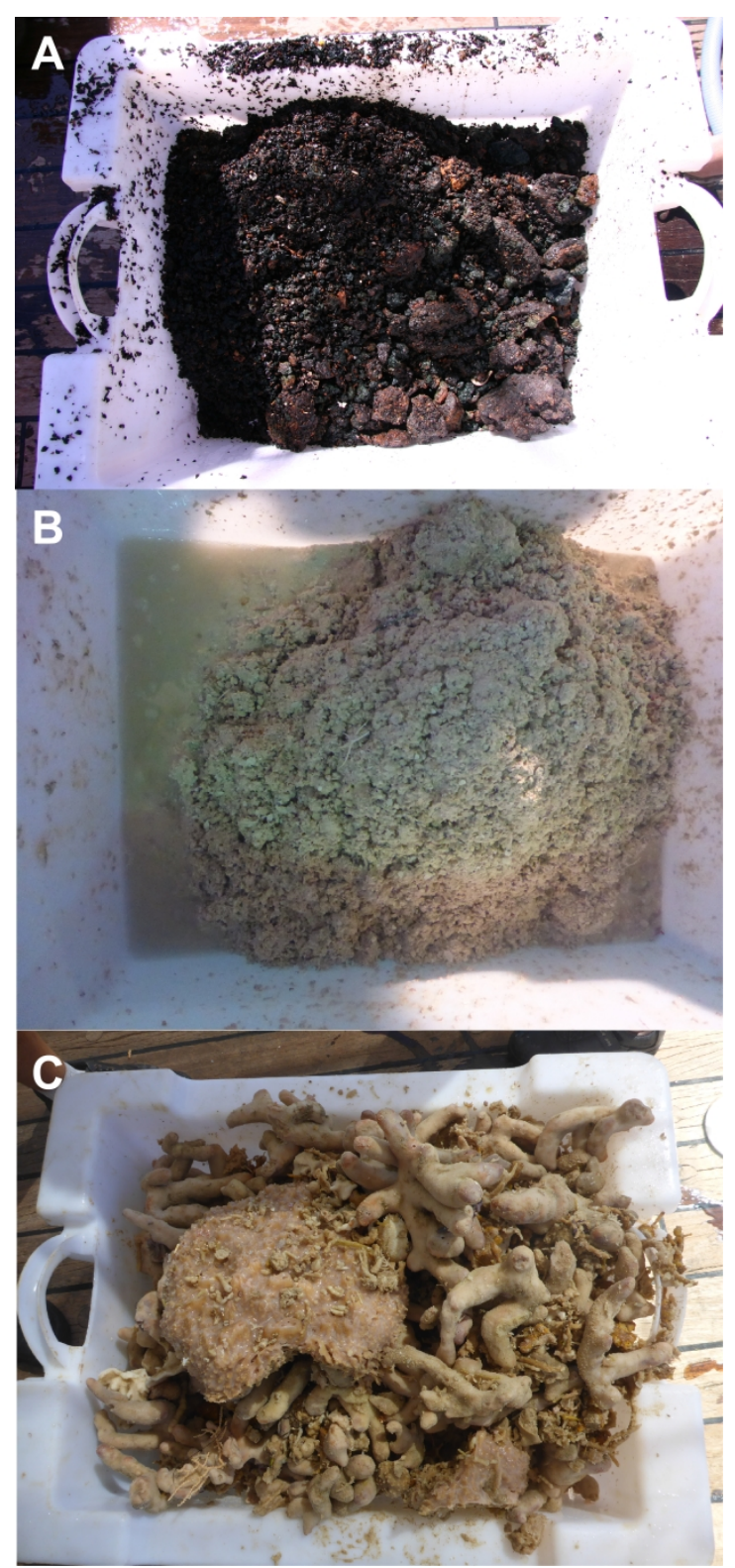

Pictures of trawls from stations were Cryptogemma tessellata (Powel, 1964) specimens were found. $433 \times 947 \mathrm{~mm}(200 \times 200$ DPI $)$ 


\section{Acknowledgments}

This work was supported by the Service de Systématique Moléculaire (UMS 2700

CNRS MNHN), the CONOTAX project funded by the French National Research Agency (grant number ANR-13-JSV7- 0013-01), the bilateral cooperation research funding from the Ministry of Science and Technology, Taiwan (grant number MOST 102-2923-B-002-001-MY3) and the French National Research Agency (grant number ANR 12-ISV7-0005-01). The contribution of Y. Kantor and A. Fedosov was supported by the grant from Russian Science Foundation no. 16-14-10118-П (PI Y. Kantor), F. Criscione and A. Hallan supported by a grant from the Australian Biological Resources Study (ABRS grant RF217-57 to PI F. Criscione), and Y. Kano by the Japan Society for the Promotion of Science (KAKENHI grant nos 15H04412 and 18H02494). The material in this paper originates from numerous shore-based expeditions and deep sea cruises, conducted respectively by MNHN and Pro-Natura International (PNI) as part of the Our Planet Reviewed programme (ATIMO VATAE, MAINBAZA, GUYANE 2014, PAPUA NIUGINI, KAVIENG 2014; PI P. Bouchet)) and/or by MNHN and Institut de Recherche pour le Développement (IRD) as part of the Tropical Deep-Sea Benthos programme (BIOMAGLO, TARASOC, MIRIKY, AURORA 2007, EBISCO, TAIWAN 2013, DongSha 2014, NANHAI 2014, BIOPAPUA, SALOMON 2, SALOMONBOA 3, CONCALIS, EXBODI, NORFOLK 2, TERRASSES, ZHONGSHA 2015, KANACONO, KANADEEP, MADEEP; PIs Bertrand Richer de Forges, Philippe Bouchet, Sarah Samadi, Nicolas Puillandre, Wei-Jen Chen, Tin-Yam Chan). Scientific partners included the University of Papua New Guinea (UPNG); National Fisheries College, Kavieng, Papua New Guinea; the National Museum of the Philippines; Institut d'Halieutique et Sciences Marines (IH.SM), Université de Tuléar, 
Madagascar; University of Taipei and University of Keelung, Taiwan; Universidade Eduardo Mondlane, Maputo; the Madagascar bureau of the Wildlife Conservation Society (WCS); and Instituto Español de Oceanografia (IOE). Funders and sponsors included the Total Foundation, Prince Albert II of Monaco Foundation, Stavros Niarchos Foundation, Richard Lounsbery Foundation, Vinci Entrepose Contracting, Fondation EDF, European Regional Development Fund (ERDF), the Philippines Bureau of Fisheries and Aquatic Research (BFAR), the French Ministry of Foreign Affairs, Fonds Pacifique and the Government of New Caledonia. Additional field work included PANGLAO 2004, a joint project of MNHN and University of San Carlos, Cebu City. All expeditions operated under the regulations then in force in the countries in question and satisfy the conditions set by the Nagoya Protocol for access to genetic resources. The authors would like to thank Virginie Héros, Barbara Buge, and Julien Brisset (MNHN) for their help in curating the vouchers; Alexander Sysoev (ZMMU) for photographs and tissue loan; Christine Zorn (ZMB) for photographs and type specimens loan; Ellen Strong, Mark. S. Florence and Kathy Hollis (USNM) for photographs and specimens loan; Jochen Gerber (FMNH) for photographs; Philippe Maestrati (MNHN) for photographs; Regina Kawamoto \& Norine Yeung (BPBM) for photographs; Severine Hannam (AWMM) for photographs; Andreia Salvador (NHMUK) for photographs;Jun Hashimoto (Nagasaki University) for organizing the Nagasaki-maru cruise N275; the Plateau Technique de Microscopie Électronique (PtME) of MNHN for SEM pictures. Posthumous thank goes to Richard Kilburn for photograph of $P$. praesignis. 